Research Article

\title{
Coaction of Wind and Rain Effects on Large-Span Hyperbolic Roofs
}

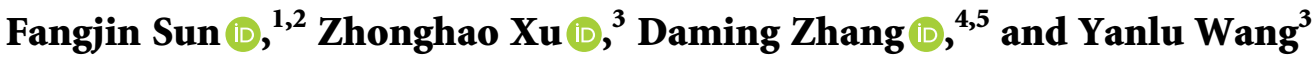 \\ ${ }^{1}$ Guangxi Key Laboratory of Geomechanics and Geotechnical Engineering, Guilin University of Technology, Guilin 541004, China \\ ${ }^{2}$ College of Civil Engineering and Architecture, Guilin University of Technology, Guilin 541004, China \\ ${ }^{3}$ College of Civil Engineering, Liaoning Technical University, Fuxin 123000, China \\ ${ }^{4}$ Guangxi Key Laboratory of Embedded Technology and Intelligence, Guilin 541006, China \\ ${ }^{5}$ College of Information Science and Engineering, Guilin University of Technology, Guilin 541006, China
}

Correspondence should be addressed to Daming Zhang; e_horse@163.com

Received 31 March 2021; Revised 12 November 2021; Accepted 3 December 2021; Published 30 December 2021

Academic Editor: Letícia Fleck Fadel Miguel

Copyright $\odot 2021$ Fangjin Sun et al. This is an open access article distributed under the Creative Commons Attribution License, which permits unrestricted use, distribution, and reproduction in any medium, provided the original work is properly cited.

\begin{abstract}
Rainfall is often accompanied by strong winds. The large-span roof structure has a low height, its surrounding turbulence is high, and the wind speed changes greatly. The effects of coaction of wind and rain on the roofs cannot be ignored. Wind-driven rain (WDR) is an oblique movement phenomenon of raindrops generated by wind flow. Four types of hyperbolic roofs, that is, square, rectangular, circular, and elliptical, are selected as the objective to study the wind-driven rain by CFD simulation. Effects of wind direction, wind speed, and rainfall intensity on the WDR are analyzed. Pressure distribution of four types of hyperbolic roofs under coaction of wind and rain is obtained. The results are compared with those from the wind action only. The roofs are partitioned to obtain the coaction of wind and rain pressure of the four large-span hyperbolic roofs with different shapes under the most unfavorable working conditions. The results show that the average pressure coefficient of the roof surface increases with the increase of wind speed and rainfall intensity. The reference value of the average pressure coefficient of wind-driven rain on the surface of the roof is given, which provides a reference basis for the design of wind-driven rain on similar hyperbolic roofs.
\end{abstract}

\section{Introduction}

Rainfall is often accompanied by strong wind. When raindrops fall, they are affected not only by their own gravity, but also by the wind speed. Therefore, the raindrops do not hit the wall and roof of the building vertically but fall at an angle. A wind-driven rain effect is generated, which usually results in an increase in the amount of rain and rain pressure load on the walls and roof of the building. The structure of the long-span hyperbolic roof is novel and widely used. Due to its low height, the surroundings have high turbulence and large changes in wind speed. Therefore, the effect of wind-driven rain on long-span hyperbolic roofs cannot be ignored. It is also of great theoretical significance and engineering value to study the pressure distribution characteristics caused by wind-driven rain in long-span hyperbolic roofs. At present, the main methods of studying structural wind load are numerical simulation $[1,2]$, wind tunnel test $[3,4]$, and field measurement $[5,6]$. Each method has its own advantages and disadvantages. The wind tunnel test technology is mature and relatively time-saving and labor-saving. Whereas the wind tunnel test simplifies the actual flow field and building shape to a certain extent, there are certain limitations, such as the reduced scale effect of the wind tunnel test. Field measurement is the most direct and basic research method, and its results are often regarded as the standard for testing other research methods. However, field measurement requires high investment and long cycle; especially it is difficult to artificially control and change the meteorological conditions and terrain conditions during field measurement. Compared with the other two methods, the numerical simulation method has the advantages of short cycle, low cost, and convenient control and can be simulated repeatedly. CFD is a new method developed in the past 40 years. Based on theoretical fluid 
mechanics and experimental fluid mechanics, CFD can simulate the flow field of different fluids well and has been widely used in the numerical simulation of various engineering flow fields.

At present, there are few studies on wind-driven rain in complex roof structures. Scholars have carried out some research on wind-driven rain in building structures and achieved some beneficial results. Choi [7-12] first inserted the rain field in the 3D wind field to calculate the raindrop trace and the WDR distribution of the windward side of the building in the 3D wind field. Sankaran [13] used CFD software for the first time to obtain the distribution of the partial pressure of the windward surface of the building in the three-dimensional wind field. After comparing with the actual model wind tunnel test data, it was found that the model values were in good agreement. $\mathrm{Wu}[14]$ used CFD to analyze the general distribution and overall trend of winddriven rain load on the windward side of low-rise buildings in $2 \mathrm{D}$ wind field and 3D wind field under different wind speed, wind direction angle, and rainfall intensity. He found that the additional load of raindrops can reach more than $30 \%$ of the strength of the windward surface of the building due to the combination of wind and rain. The application of the Euler-Euler frame to the study of wind-driven rain was recognized by scholars in the early twenty-first century. Kubilay [15, 16], Pettersson [17], and Wang [18, 19] et al. applied the CFD numerical simulation method that introduced the Euler multiphase flow model to the field of building WDR research and compared it with the existing measured data. The results show that the numerical simulation results are in good agreement with the field measurements. Compared with the Euler-Lagrange method, the Euler-Euler method regards the rain phase as continuous, and it is suitable for the mass conservation equation, the momentum conservation equation, and the energy conservation equation similar to the continuous wind phase. The Euler-Lagrange method requires a stable wind field to be used to define the rain phase when studying wind-driven rain. Unlike the Euler-Lagrange method, the Euler-Euler method can define the rain phase boundary conditions by different rain phase velocity and rain phase volume fraction when defining the wind phase boundary, which greatly reduces the calculation amount and workload, and can obtain various field maps in the wind and rain joint field.

In this paper, the Euler-Euler method is used to numerically simulate the four hyperbolic roofs of square, rectangular, circular, and elliptical shapes, and the influence of wind speed, wind direction angle, and rain intensity on the surface pressure of the four hyperbolic roofs is studied. In Section 2, we introduce the settings of wind and rainrelated parameters and their theories. In Section 3, we conduct numerical simulations on the four hyperbolic roofs under different parameters and analyze the influence of the wind-driven rain surface pressure. In Sections 4, the hyperbolic roof is partitioned, and reasonable recommended values are proposed. Finally, Sections 5 and 6 provide a general discussion and conclusion, respectively.

\section{Methodology}

\subsection{Euler-Eulerian Control Equations}

(1) Wind phase governing equation:

$$
\begin{aligned}
\frac{\partial u_{j}}{\partial x_{j}}= & 0 \\
\frac{\partial \rho_{a} u_{i}}{\partial t}+\frac{\partial\left(\rho_{a} u_{i} u_{j}\right)}{\delta x_{j}}= & -\frac{\partial p}{\partial x_{i}}+\frac{\partial \tau_{i j}}{\delta x_{j}}, \\
\frac{\partial \rho_{a}}{\partial t}+\frac{\partial\left(\rho_{a} k u_{j}\right)}{\delta x_{j}}= & \frac{\partial}{\partial x_{j}}\left[\left(\mu+\frac{\mu_{t}}{\sigma_{k}}\right) \frac{\partial k}{\delta x_{j}}\right]+G_{k}-\rho a, \\
\frac{\partial \rho \varepsilon}{\partial t}+\frac{\partial\left(\rho_{a} \varepsilon u_{j}\right)}{\delta x_{j}}= & \frac{\partial}{\partial x_{j}}\left[\left(\mu+\frac{\mu_{t}}{\sigma_{\varepsilon}}\right) \frac{\partial \varepsilon}{\delta x_{j}}\right] \\
& +C_{1} \frac{\varepsilon}{k} G_{k}-C_{2 \varepsilon} \rho_{a} \frac{\varepsilon^{2}}{k}, \\
\mu_{t}= & C_{\mu} \rho_{a} \frac{K^{2}}{\varepsilon},
\end{aligned}
$$

where $\rho_{a}$ is the air density, $k$ is the turbulent flow energy, $\varepsilon$ is the turbulent dissipation rate, $\sigma_{k}$ and $\sigma_{\varepsilon}$ are the turbulent Prandtl numbers of $k$ and $\varepsilon$, respectively, $\mu$ is the aerodynamic viscosity coefficient, $\tau_{i j}$ is Reynolds stress, $\mu_{t}$ is turbulent viscosity, and the constant $C_{1 \varepsilon}=1.44, C_{2 \varepsilon}=1.92, C_{\mu}=0.09$.

(2) Rain phase governing equation:

$$
\begin{aligned}
\frac{\delta \rho_{w} \alpha_{k} u_{k i}}{\delta t}+\frac{\delta\left(\rho_{w} \alpha_{k} u_{k j}\right)}{\delta x_{j}}=\rho_{w} \alpha_{k} g+\rho_{w} \alpha_{k} \frac{3 \mu}{\rho_{w} d^{2}} \frac{C_{d} R_{e_{R}}}{4}\left(u_{i}-u_{k i}\right), \\
\frac{\delta \rho_{w} \alpha_{k}}{\delta t}+\frac{\delta\left(\rho_{w} \alpha_{k} u_{k j}\right)}{\delta x_{j}}=0,
\end{aligned}
$$

where $\rho_{w}$ is the rainwater density, $C_{d}$ is the drag coefficient of rain, $u_{i}$ is the wind velocity component in the $i$ direction, $u_{k i}$ is the absolute velocity component of the $i$-th raindrop, $\mu$ is the aerodynamic viscosity coefficient, $R_{e_{R}}$ is the relative Reynolds number of wind and rain, and the formula is as follows:

$$
R_{e_{R}}=\frac{\rho_{a} d}{\mu}\left|\vec{u}-\overrightarrow{u_{k}}\right|
$$

2.2. Boundary Conditions of Wind Field. The boundary conditions are set as follows:

(1) Inlet conditions 
Inlet speed setting: the inlet adopts the exponential rate wind speed section boundary condition, and the equation is as follows:

$$
V_{Z}=V_{G}\left(\frac{Z}{Z_{G}}\right)^{\alpha} \text {, }
$$

where $V_{G}=16.7 \mathrm{~m} / \mathrm{s}$ is the average wind speed at the reference height, $Z_{G}=10 \mathrm{~m}$ is the reference height, and $\alpha$ is the ground roughness exponent, $\alpha=0.16$.

Inlet turbulence parameter setting: take the Japanese code [20] for the definition of turbulence intensity, and the equation is as follows:

$$
I_{u}= \begin{cases}0.23, & z \leq z_{b}, \\ 0.1\left(\frac{z}{z_{g}}\right)^{-\alpha-0.05}, & z_{b<z \leq z_{g}}, \\ 0.1, & z>z_{g} .\end{cases}
$$

In the equation, $\alpha=0.16, z_{b}=5 \mathrm{~m}, z_{g}=450 \mathrm{~m}$.

The turbulent kinetic energy $k$ and the turbulent dissipation rate $\varepsilon$ are, respectively, as follows:

$$
\begin{aligned}
& k(z)=1.5[I(z) \bar{u}(z)]^{2}, \\
& \varepsilon(z)=\frac{C_{\mu}^{3 / 4} k(z)^{3 / 2}}{\kappa L_{u}},
\end{aligned}
$$

where $\bar{u}(\mathrm{z})$ is the average wind speed at the windward, $L_{u}$ is the length scale of turbulence at the windward, $C_{\mu}=0.09$, and $\kappa=0.4$.

(2) Outlet conditions: complete outflow boundary conditions.

(3) Wall boundary conditions: both sides and top surface of the domain adopt slip boundary conditions, and the surface of the building surface adopts no slip boundary conditions.

2.3. Settings of Rain Field. At present, the main problems in the numerical simulation of the rain field are as follows: the end velocity of raindrops, the distribution law of raindrops with different particle sizes, etc. This paper is to carry out research work on a certain basis and cannot be applied to all regions.

(1) Rain intensity

The rainfall intensity is the amount of rainfall per unit time. Table 1 shows the classification of rainfall levels.

(2) Raindrop diameter distribution

This paper uses the modified $\Lambda$ distributed raindrop spectrum function, and the formula is as follows [21]:

$$
\begin{aligned}
N(D, R) & =N_{0} D^{\alpha} \exp (-\Lambda D), \\
N_{0}(R) & =1.98 \times 10^{7} R^{-0.384}, \\
\Lambda(R) & =5.38 R^{-0.186}
\end{aligned}
$$

where $N(D, R)$ represents the number of raindrops in the range of unit volume size difference $\mathrm{d} D$, the constant $\alpha=2.93$, and $N$ and $\Lambda$ are functions of rain intensity $R$.

(3) Terminal velocity of raindrops

Without interference from surrounding buildings, the formula for the terminal velocity of raindrops is as follows [22]:

$$
V_{t}(D)= \begin{cases}0 ; & D \leq 0.03 \mathrm{~mm} \\ 4.323(D-0.03) ; & 0.03<D \leq 0.6 \mathrm{~mm} \\ 9.65-10.3 \exp (-0.6 D) ; & D>0.6 \mathrm{~mm}\end{cases}
$$

(4) Rain phase boundary conditions

The boundary condition of the rain phase windward is to first define the rain phase volume fraction of raindrops of different diameters and then set the parameters of the raindrop velocity and turbulence intensity at the entrance boundary of the watershed field. In order to take into account different raindrop diameters, this paper introduces the volume fraction of rain phases with different diameters according to reference [23], and the formula is as follows:

$$
\begin{gathered}
a_{k}=\frac{R_{h} f_{h}\left(D, R_{h}\right)}{v_{t}(D)} \frac{1 \times 10^{-3}}{3600}, \\
f_{h}\left(D, R_{h}\right)=\frac{D^{3} N\left(D, R_{h}\right) v_{t}(D)}{\int_{0}^{\infty} D^{3} N\left(D, R_{h}\right) v_{t}(D) \mathrm{d} D},
\end{gathered}
$$

where $a_{k}$ is the volume fraction, $f_{h}\left(D, R_{h}\right)$ is the raindrop flow fraction with diameter $D, R_{h}$ is the horizontal rainfall intensity, and $N\left(D, R_{h}\right)$ is the number of raindrops within the unit volume size difference $\mathrm{d} D$.

This paper uses Euler-Euler multiphase flow to study the effect of wind and rain on large-span roof structures. In the numerical simulation of the continuous medium rain field, raindrops are regarded as continuous phases rather than discrete phases, which is also beneficial to obtain various cloud images. Therefore, to define the rain load, the formula is as follows:

$$
p_{\text {rain }}=\int_{0}^{\infty} \rho_{l} a_{D}(D)\left|V_{n}(D)\right|^{2} \mathrm{~d} D,
$$

where $V_{n}(D)$ is the normal velocity when raindrops hit a large-span roof structure, and $\rho_{l}$ is the density of liquid water. 
TABLE 1: The practical application of rainfall classification.

\begin{tabular}{|c|c|c|c|c|c|c|c|c|}
\hline \multirow{2}{*}{ Grade } & \multirow{2}{*}{ Flurry } & \multirow{2}{*}{ Middle flurry } & \multirow{2}{*}{ Drencher } & \multirow{2}{*}{ Rainstorm } & \multicolumn{4}{|c|}{ Heavy rainstorm } \\
\hline & & & & & Weak & Middle & Strong & Extremum \\
\hline Rainfall $(\mathrm{mm} / \mathrm{h})$ & 2.5 & 8 & 16 & 32 & 64 & 100 & 200 & 709.2 \\
\hline
\end{tabular}

\section{Numerical Simulation of Wind-Driven Rain}

3.1. Model. This paper takes the large-span hyperbolic roof structure as the calculation model, as shown in Figure 1 (see Table 2 for details). An experimental scale model [24-26] was established in Gambit. The length of the building is $L_{2}$, the width of the building is $L_{1}$, and the maximum height of the building is $H_{\max }$. After many calculations and comparisons, the size of the calculation domain is taken as $L_{1} \times L_{2} \times H=8 \mathrm{~m} \times 16 \mathrm{~m} \times 2.133 \mathrm{~m}$. The calculation model meets the requirement that the maximum blocking rate is less than $3 \%$, which is at the third of the windward side of the calculation domain. In this paper, the measurement directions 1, 2 are selected. Direction 1 is the convex parabola of the roof centerline, and direction 2 is the parabola of the roof centerline concave direction.

The turbulence model in this paper selects the Euler-Euler model in the rain phase and the standard $\mathrm{k}-\varepsilon$ model in the wind phase, which simplifies the calculation process. After selecting the calculation model and the size of the calculation domain, this paper adopts a hybrid meshing method considering the accuracy and convergence of the numerical simulation. The core area of the calculation basin is divided by a well-adapted irregular tetrahedral mesh, and the noncore area is divided by a hexahedral mesh (see Figure 2). The grid is encrypted in the building area, and grids are gradually sparse apart from building, the minimum grid size is $0.05 \mathrm{~m}$, and the number of grids is about 1.3 million.

The standard wall functions are selected for the calculation model near the wall, the SIMPLE algorithm is selected in the solution method, the gradient Green-Gauss Cell Based is selected, and the momentum, turbulent kinetic energy, and turbulent energy dissipation rate are selected as the second-order upwind difference format to monitor residuals. The difference and static pressure interfaces are, respectively, set at the entrance and exit of the calculation domain based on the area-weighted average. When the average weighted pressure curve on the interface changes regularly, the calculation is converged. Numerical simulation calculation can be performed after the above parameter setting is completed.

The numerical simulation result is expressed by the average pressure coefficient $C_{p}$, and the positive and negative values of $C_{p}$ are determined by the pressure. And when the pressure direction is downward, the pressure value is positive, and the upward value is negative. The formula is as follows:

$$
\begin{aligned}
C_{p} & =\frac{P_{i}-P_{0}}{q_{m}} \\
& =\frac{P_{i}-P_{0}}{1 / 2 \rho v_{m}^{2}},
\end{aligned}
$$

where $P_{i}$ is the pressure at point $i$ on the building surface, $P_{0}$ is the static pressure of the free flow, $q_{m}$ is the average dynamic pressure of the free flow, $\rho$ is the air density, and $v_{m}$ is the average speed of the free flow.

Before the numerical simulation of the large-span hyperbolic roof structure under wind-driven rain, the numerical simulation was carried out when the wind speed was $16.7 \mathrm{~m} / \mathrm{s}$, and the wind direction angles were $0^{\circ}, 45^{\circ}$, and $90^{\circ}$. And the results of the numerical simulation were compared with the wind tunnel test results of Fabio Rizzo et al. [25]. As shown in Figure 3, the simulation results are in good agreement with the wind tunnel test results, which proves the accuracy of the simulation.

\subsection{The Influence of Wind Direction Angle on the Pressure} Distribution of Hyperbolic Roofs. This section first simulates the pressure situation when the rainfall intensity is $32 \mathrm{~mm} / \mathrm{h}$, the wind speed is $16.7 \mathrm{~m} / \mathrm{s}$, and the square hyperbolic roof (M1) under different wind direction $\left(0^{\circ}, 45^{\circ}, 90^{\circ}\right)$. The winddriven rain pressure is compared with the pressure when the wind acts alone. The details are shown in Figure 4.

(1) It can be seen from Figure 4(a):

At $0^{\circ}$ wind direction, the simulated average pressure coefficient $C_{p s}$ and the experimental average pressure coefficient $C_{p \text { test }}$ are both negative, and the simulated average pressure coefficient is larger than the experimental average pressure coefficient. The simulation curve begins to decrease and then stabilizes. The maximum value of $C_{p s} / C_{p \text { test }}$ is about 2.2 , and the minimum value is about 1.36 . The maximum value of the simulated average pressure coefficient appears at the front part of the curve, indicating that the front part of the roof is under greater force.

(2) It can be seen from Figures 4(b) and 4(c):

In the direction 2 ( $45^{\circ}$-wind direction), the value of $C_{p s} / C_{p t e s t}$ is relatively large. The largest ratio appears at the front of the roof, about 2.54, and the smallest ratio appears at the end of the curve, about 1.33. In the direction $1\left(45^{\circ}\right.$-wind direction), the value of $C_{p s} / C_{p t e s t}$ is about 1.5-2.6. The simulation curves in both directions first decrease, change quickly, and then become stable. At the wind direction of $45^{\circ}$, the maximum average pressure coefficient under winddriven rain is at the front part of the roof.

(3) It can be seen from Figure 4(d):

At a wind direction of $90^{\circ}$, the simulation curve resembles an upward opening parabola, and the maximum average pressure coefficient appears in the middle of the curve. At the front part of the simulation curve, $C_{p s}$ is slightly smaller than $C_{p \text { test }}$, 


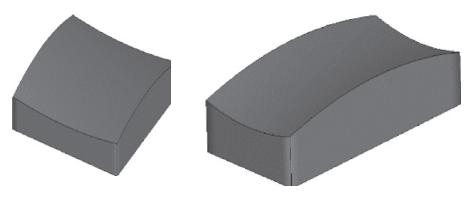

(a) (b)

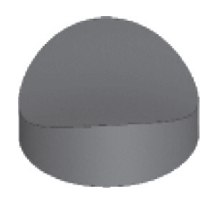

(c)

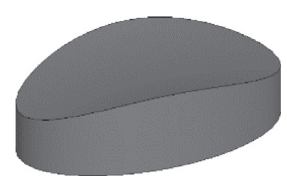

(d)

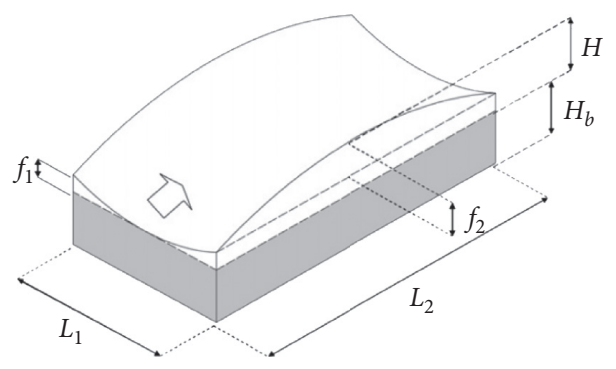

(e)

Figure 1: Calculation model of four different shapes of large-span hyperbolic roof structures [24]. (a) M1. (b) M2. (c) M3. (d) M4. (e) Parameter definition.

TABLE 2: The raindrop number density.

\begin{tabular}{lcccccccccc}
\hline Model & $L_{1} / \mathrm{m}$ & $L_{2} / \mathrm{m}$ & $\delta$ & $H_{\mathrm{b}} / \mathrm{m}$ & $\rho$ & $H / \mathrm{m}$ & $f_{1} / \mathrm{m}$ & $f_{2} / \mathrm{m}$ & $H_{\max } / \mathrm{m}$ & 0.0267 \\
\hline Square hyperbolic roof & $\mathrm{M} 1$ & 0.8 & 0.8 & $1 / 6$ & 0.1333 & $1 / 10$ & 0.08 & 0.0533 & 0.2133 \\
Rectangular hyperbolic roof & $\mathrm{M} 2$ & 0.4 & 0.8 & $1 / 6$ & 0.1333 & $1 / 10$ & 0.08 & 0.0267 & 0.0533 & 0.2133 \\
Circular hyperbolic roof & $\mathrm{M} 3$ & 0.8 & 0.8 & $1 / 6$ & 0.1333 & $1 / 10$ & 0.08 & 0.0267 & 0.0533 & 0.2133 \\
Elliptical hyperbolic roof & $\mathrm{M} 4$ & 0.4 & 0.8 & $1 / 6$ & 0.1333 & $1 / 10$ & 0.08 & 0.0267 & 0.0533 & 0.2133 \\
\hline
\end{tabular}

Note: $\rho=H / L_{\max }, \delta=H_{b} / L_{\max } \cdot L_{\max }=0.8 \mathrm{~m}$

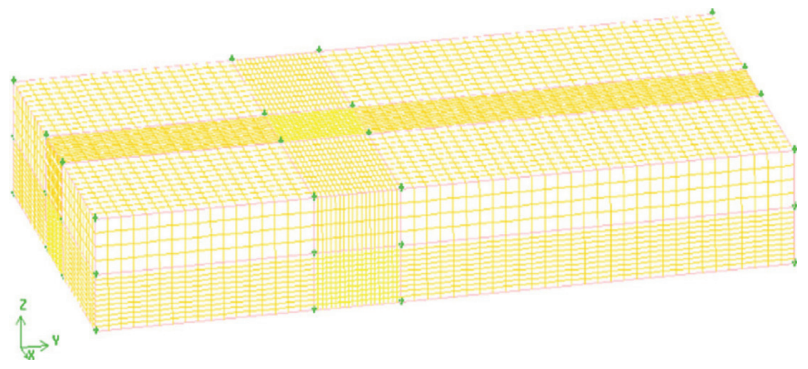

FIgURE 2: The diagram of flow field mesh.

because the rain pressure is larger than the wind suction; after that, $C_{p s}$ is larger than $C_{\text {ptest }}$, and the maximum value of $C_{p s} / C_{p \text { test }}$ is about 10 , indicating that the middle of the roof is strongly affected.

It can be concluded from Figure 4 that the average pressure coefficient of the square hyperbolic roof surface under wind-driven rain is larger than that of the wind alone, and the combined effect of wind and rain on the hyperbolic roof cannot be ignored. Under wind-driven rain, the square hyperbolic roof is mainly subjected to suction. At $0^{\circ}, 45^{\circ}$, and $90^{\circ}$ wind direction angles, the average pressure coefficient trends of the square hyperbolic roof surface under winddriven rain are different.

Then, the calculation models M1, M2, M3, and M4 are selected. The calculation conditions are shown in Table 3. The numerical simulation of wind-driven rain on the surfaces of four hyperbolic roofs is performed under different wind direction angles. Figure 5 is a schematic diagram of the wind direction angle. The average pressure coefficient distribution diagrams are shown in Figure 6-9.

(1) It can be seen from Figure 6:
At a wind direction angle of $0^{\circ}$, the square roof surface is distributed in a uniform gradient shape. Due to the separation and reattachment of the airflow in the windward concave surface, the average pressure coefficient of the front end of the roof windward surface is large, and the gradient changes greatly, showing a peak of -2.6 . The surface of the roof all shows a high negative pressure distribution, so that the entire roof structure is subjected to a large suction force. At $30^{\circ}, 45^{\circ}$ and $60^{\circ}$ wind direction angles, the average pressure coefficient of the front edge of the roof on the windward surface is relatively large, and the average pressure on the surface of the roof is generally conical, and the average pressure coefficient gradually decreases along the gradient. At a $90^{\circ}$ wind direction angle, the windward surface of the roof is convex, the airflow is reduced, and the average pressure coefficient is also reduced. At $\left[0^{\circ}\right.$, $45^{\circ}$ ], the average pressure coefficient increases with increasing angle, then decreases, and then increases again. At $\left[45^{\circ}, 90^{\circ}\right]$, the average pressure coefficient decreases with increasing the angle.

Under different wind direction angles, the average pressure coefficient of the surface of the square hyperbolic roof is negative, and its surface is affected by suction. The maximum value appears at the front edge of the surface of the square hyperbolic roof, and the most unfavorable wind direction angle for the square hyperbolic roof structure is $0^{\circ}$.

(2) It can be seen from Figure 7:

At an angle of $0^{\circ}$ wind direction, the average pressure on the surface of the rectangular roof has a gradient distribution, and the average pressure coefficient at the front end of the roof surface is large, and the gradient changes greatly. At a wind direction angle of 


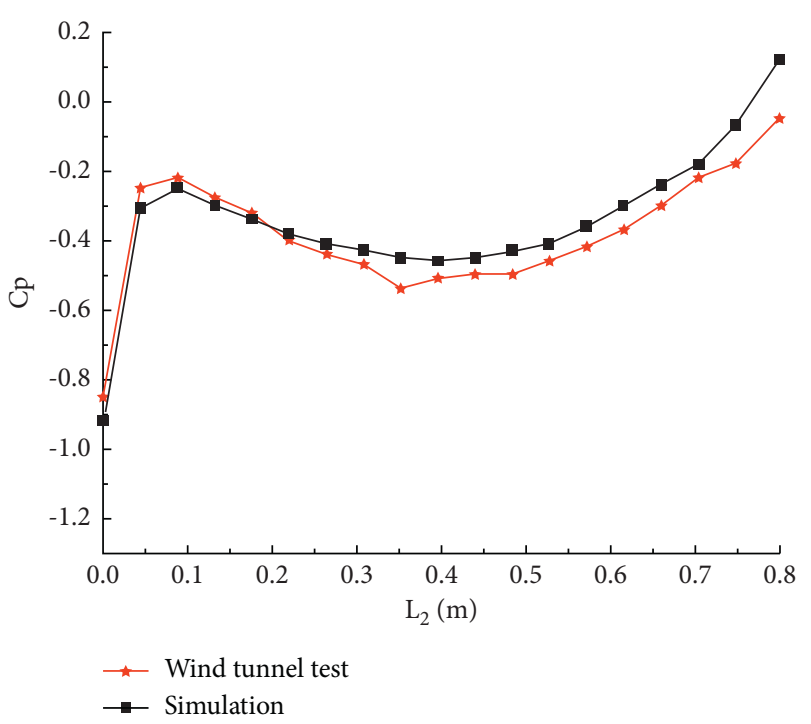

(a)

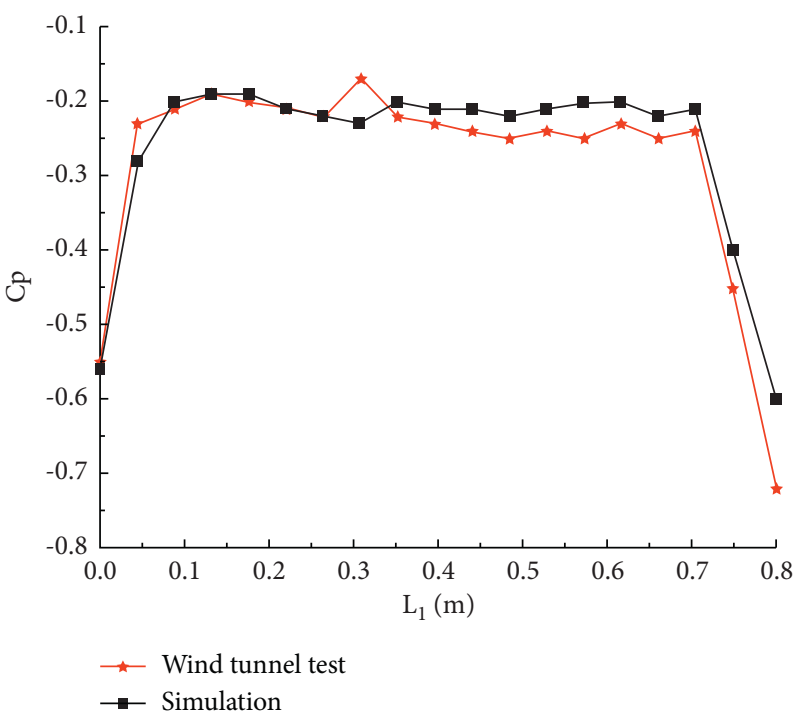

(c)

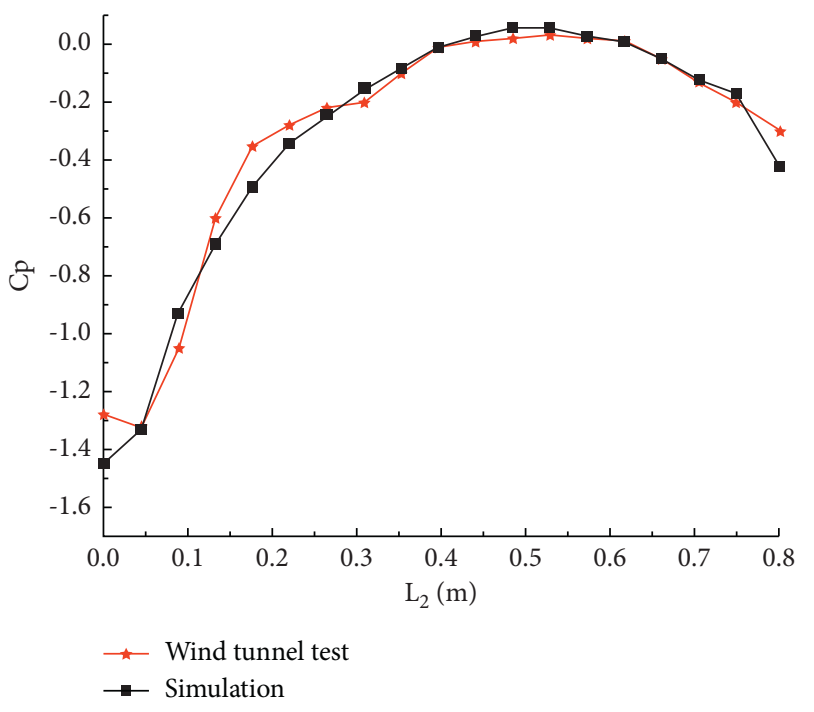

(b)

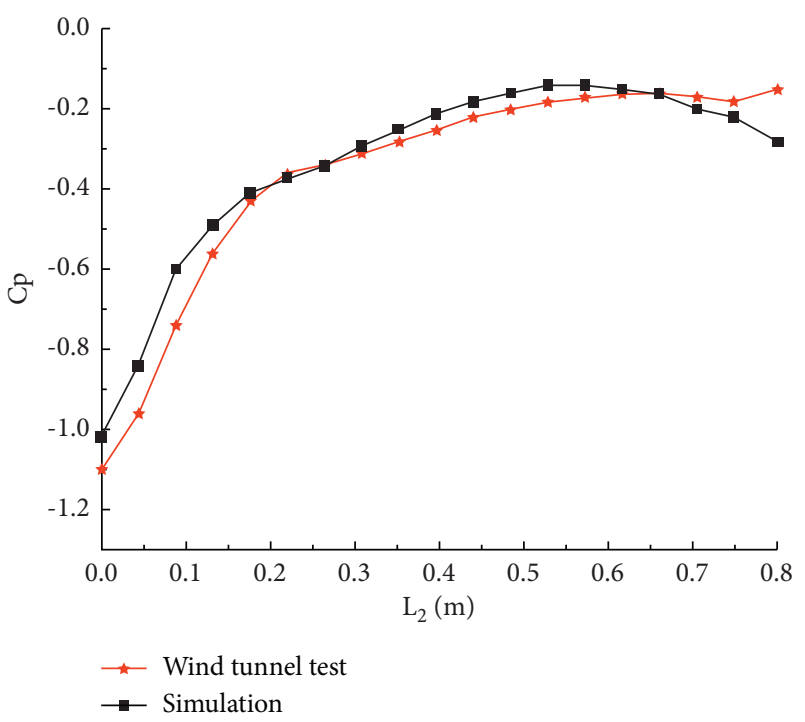

(d)

Figure 3: Comparison of simulation data and wind tunnel data results. (a) $0^{\circ}$ direction 1. (b) $45^{\circ}$ direction 1 . (c) $45^{\circ}$ direction 2 . (d) $90^{\circ}$ direction 1.

$30^{\circ}$, the average pressure coefficient at the front edge and right side of the roof of the windward surface is larger, and the distribution is more uniform, and then the average pressure coefficient gradually decreases along the wind flow direction. At $45^{\circ}$, the airflow separates at the corners and acts extremely strongly at the attachments, making the average pressure on the front edges of both sides of the roof facing the wind larger and the gradient change large, with a peak value of -1.9 . At $60^{\circ}$, the average pressure coefficient at the front edge of the roof is larger, and the average pressure coefficient decreases in sequence along the direction of the airflow, and the average pressure coefficient on the roof surface is unevenly distributed. At $90^{\circ}$, both sides of the front edge of the roof surface of the windward surface are distributed in small columns, and the average pressure coefficient first increases to reach the peak value of -1.7 and then decreases. In the range of $\left[0^{\circ}\right.$, $90^{\circ}$ ], the average pressure coefficient does not decrease with the increase of the angle, and there is no obvious law with the change of the angle. The airflow separation at the front end of the roof facing the wind is the most serious, where the average pressure coefficients are large and peak.

The average pressure coefficient of the surface of the rectangular hyperbolic roof all shows a large negative value, indicating that the roof surface is under suction. The average pressure coefficient of the air flow to the front edge of the rectangular hyperbolic roof is large and appears extreme. The average pressure coefficient of the surface of the rectangular hyperbolic roof varies with angle without obvious rules. 


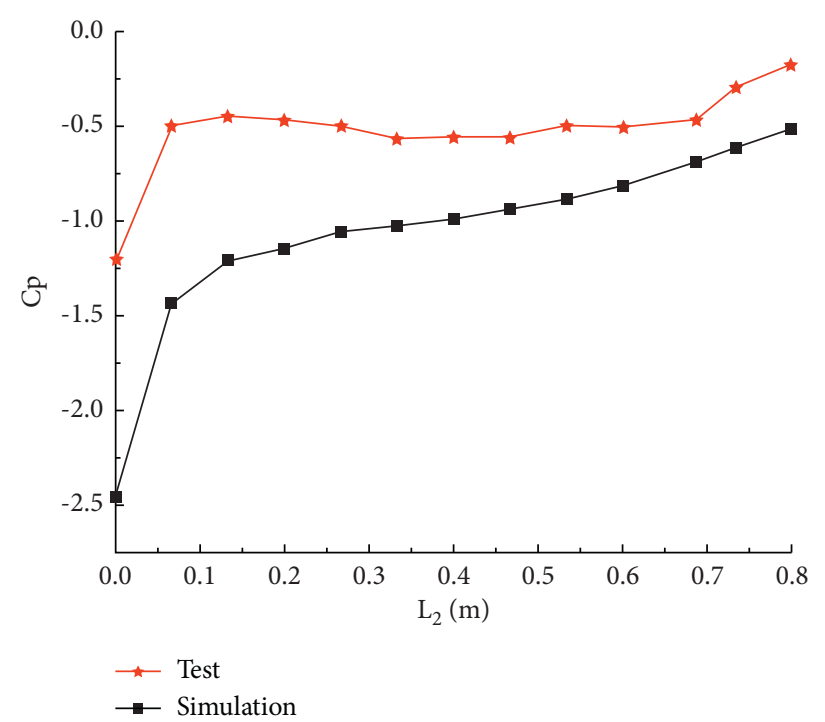

(a)

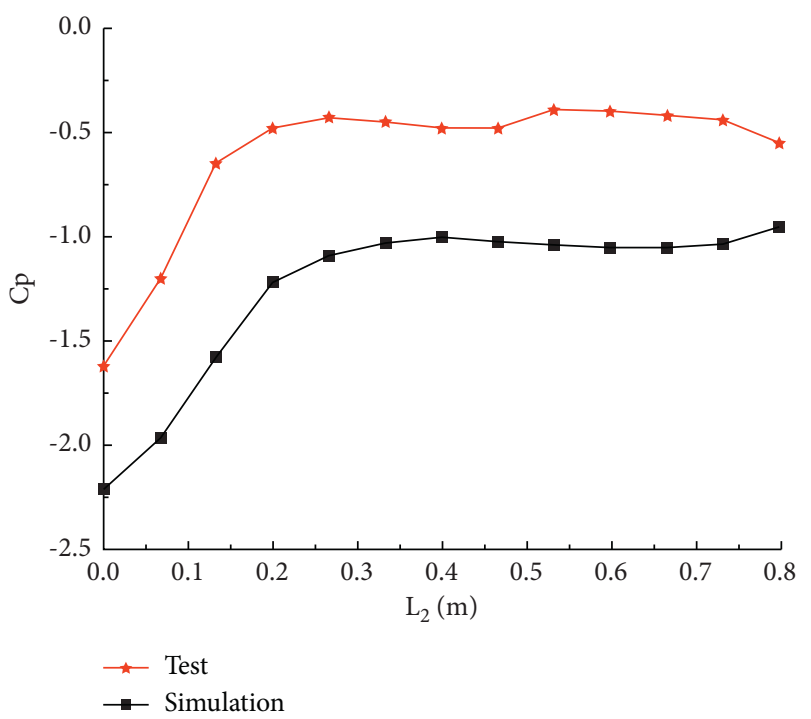

(c)

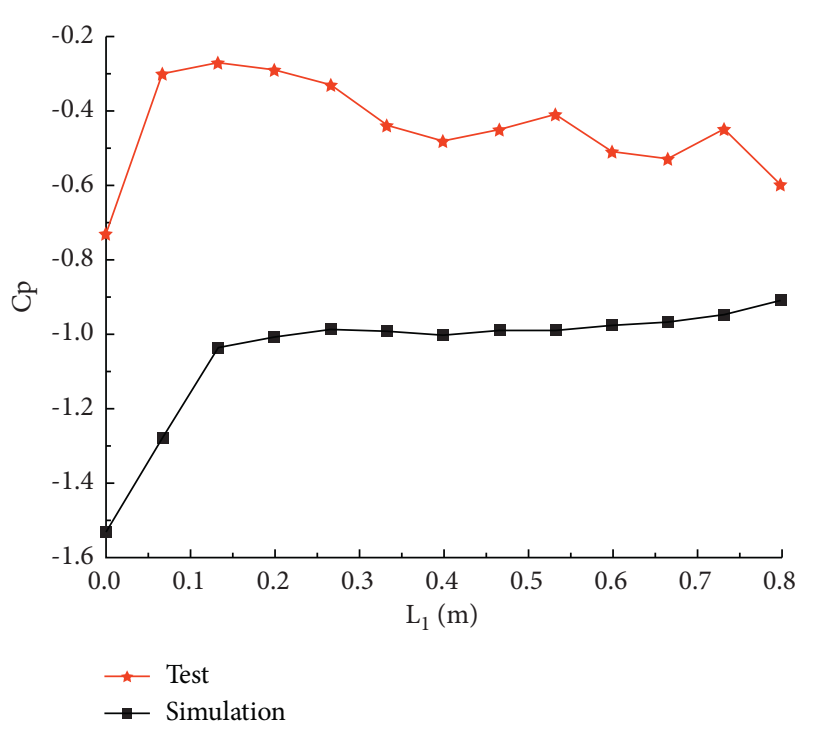

(b)

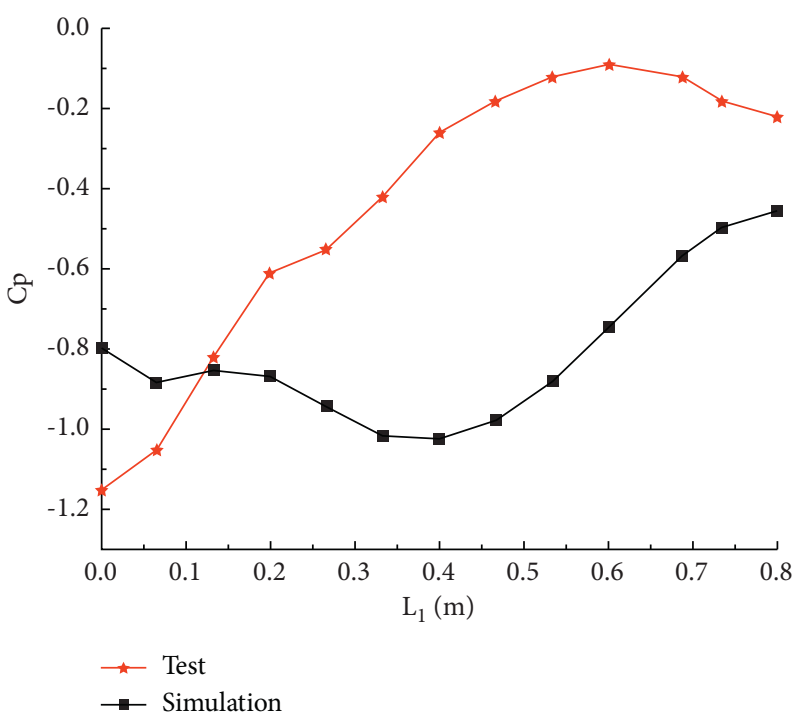

(d)

FIgURE 4: The average $C_{p}$ of measured points on the central axis of the roof. (a) $0^{\circ}$ direction 1 . (b) $45^{\circ}$ direction 2 . (c) $45^{\circ}$ direction 1 . (d) $90^{\circ}$ direction 2.

TABLE 3: Simulation conditions.

\begin{tabular}{lccc}
\hline Condition & Wind direction angle & Wind speed & Rainfall intensity \\
\hline a & $0^{\circ}$ & & \\
b & $30^{\circ}$ & & \\
c & $45^{\circ}$ & $10 \mathrm{~m} / \mathrm{s}$ & $32 \mathrm{~mm} / \mathrm{h}$ \\
d & $60^{\circ}$ & & \\
e & $90^{\circ}$ & & \\
\hline
\end{tabular}

(3) It can be seen from Figure 8:

At $0^{\circ}$ and $30^{\circ}$ wind direction angles, the average pressure coefficient of the circular roof first decreases and then increases, the average pressure coefficient at the front end of the roof is larger, and the gradient changes greatly. At $45^{\circ}$ and $60^{\circ}$, the roof surface is

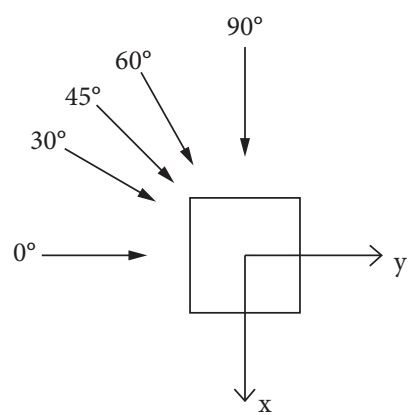

Figure 5: The schematic diagram of wind direction.

distributed like inverted cone and positive cone. The average pressure coefficient of the roof surface has positive and negative values, indicating that, under 


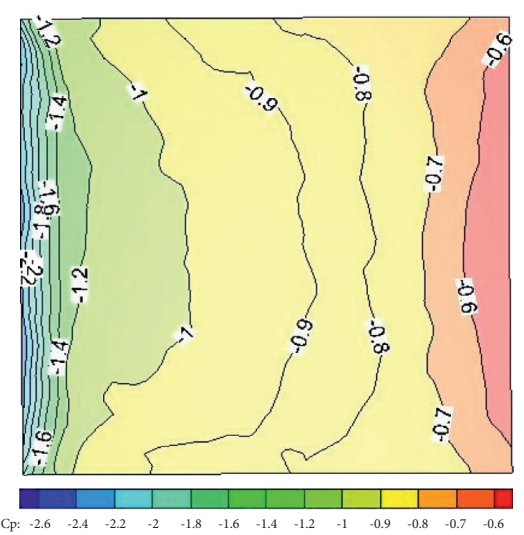

(a)

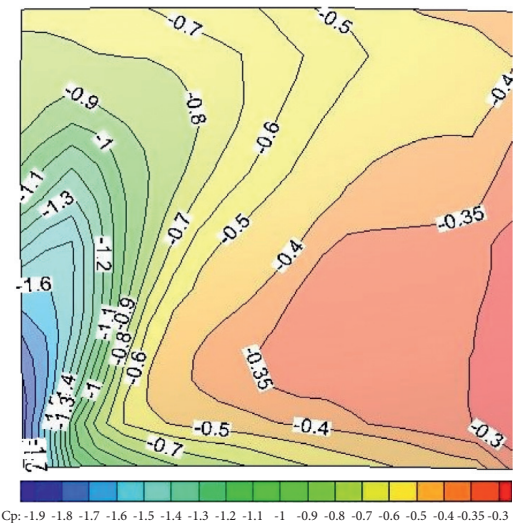

(d)
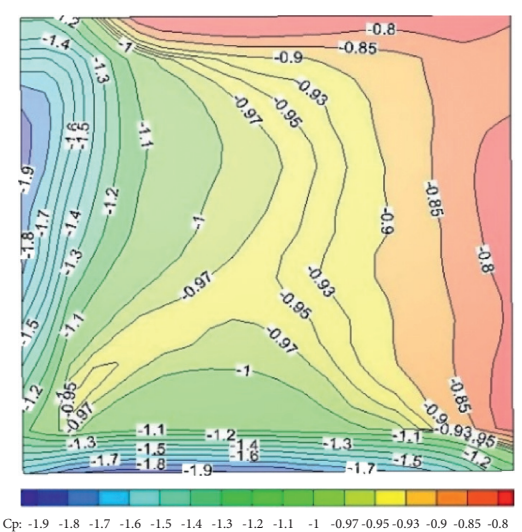

(b)

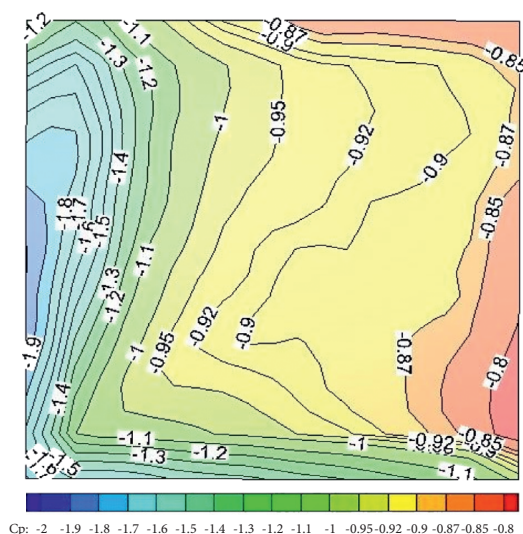

(c)

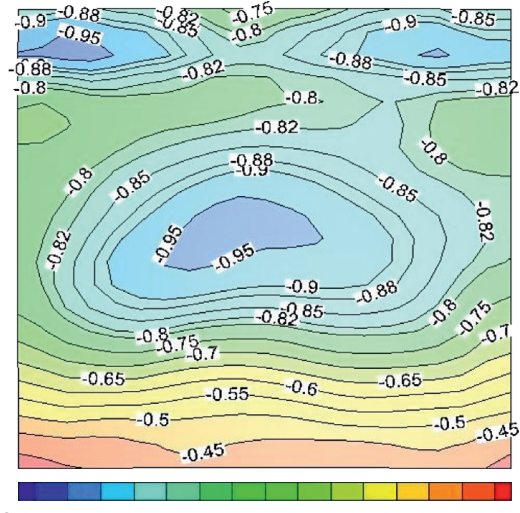

(e)

FIgure 6: The distribution of $C_{p}$ on the surface of the square hyperbolic roof. (a) $0^{\circ}$, (b) $30^{\circ}$. (c) $45^{\circ}$. (d) $60^{\circ}$. (e) $90^{\circ}$.

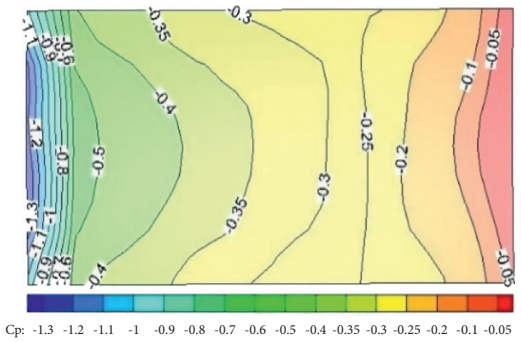

(a)
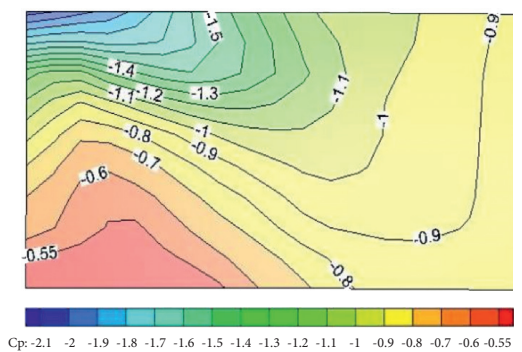

(d)

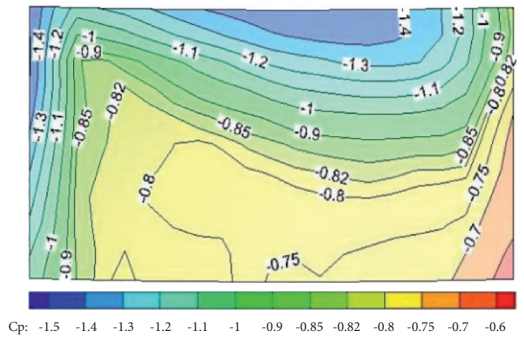

(b)

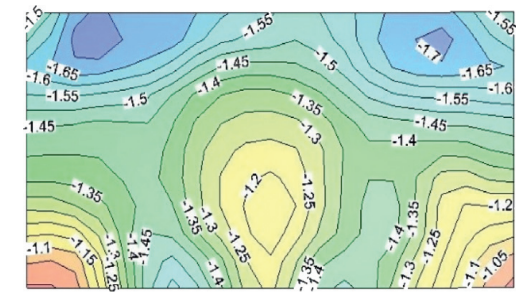

Cp: $-1.75-1.7-1.65-1.6-1.55-1.5-1.45-1.4-1.35-1.3-1.25-1.2-1.15-1.1-1.05-1$

(e)

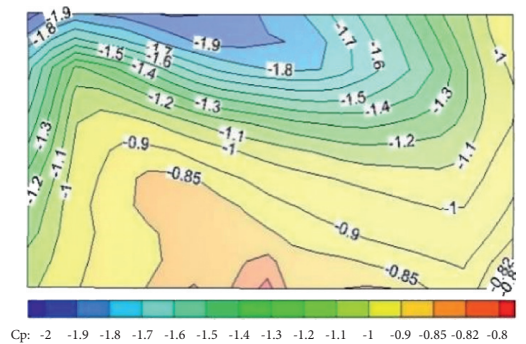

(c)

Figure 7: The distribution of $C_{p}$ on the surface of the rectangular hyperbolic roof. (a) $0^{\circ}$. (b) $30^{\circ}$. (c) $45^{\circ}$. (d) $60^{\circ}$. (e) $90^{\circ}$. 

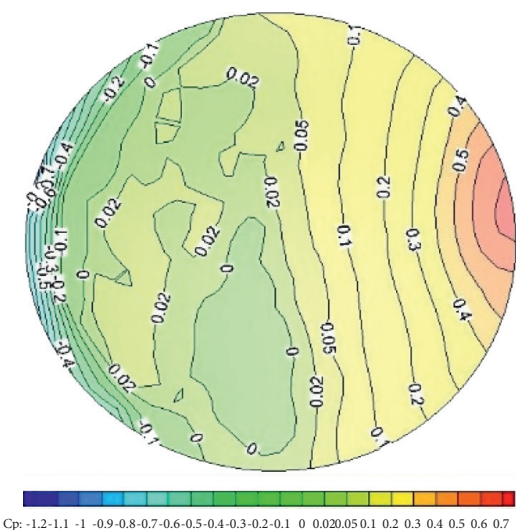

(a)

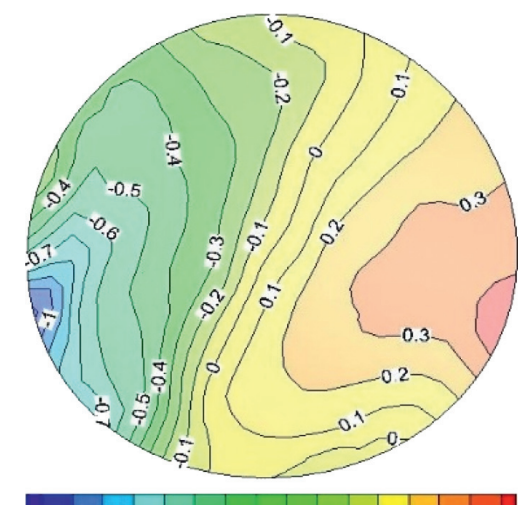

(d)

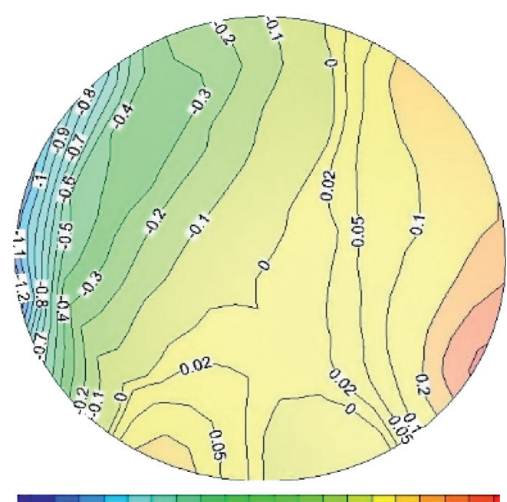

(b)

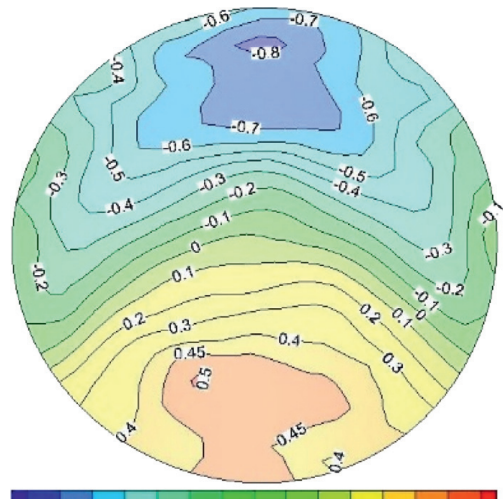

(e)

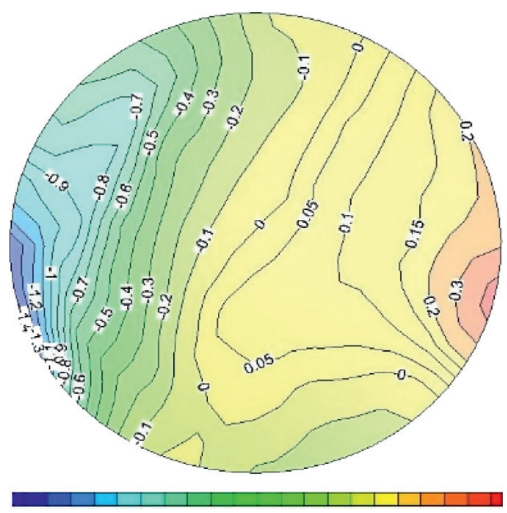

(c)

FIgURE 8: The distribution of $C_{p}$ on the surface of the circular hyperbolic roof. (a) $0^{\circ}$. (b) $30^{\circ}$. (c) $45^{\circ}$. (d) $60^{\circ}$. (e) $90^{\circ}$.

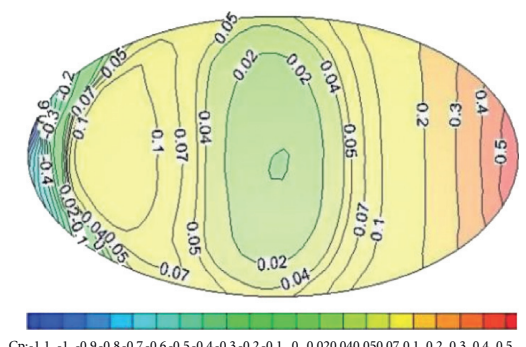

(a)

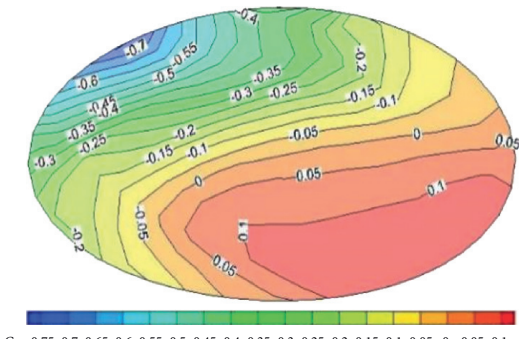

(d)

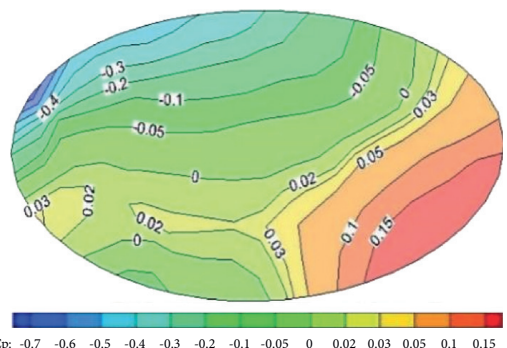

(b)

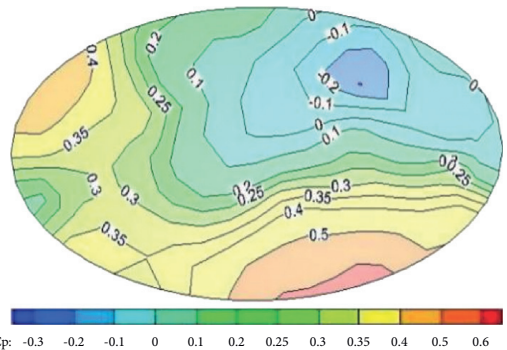

(e)

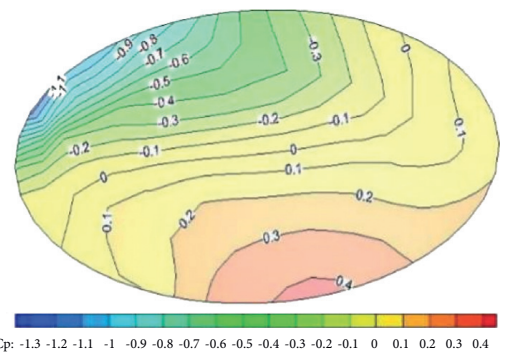

(c)

Figure 9: The distribution of $C_{p}$ on the surface of the elliptical hyperbolic roof. (a) $0^{\circ}$. (b) $30^{\circ}$. (c) $45^{\circ}$. (d) $60^{\circ}$. (e) $90^{\circ}$. 
the combined action of wind and rain, wind suction and rain pressure may also be possible. It is caused by a series of complex effects of wind pressure; the average pressure coefficient at the middle of the roof surface is zero, and the location is safe. At $90^{\circ}$, the roof surface is more evenly distributed, and the average pressure coefficient first increases to the extreme value, then decreases to 0 , and then slowly increases. The average pressure coefficient of the roof surface is 0 in the middle, positive and negative value offset.

The average pressure coefficient of the surface of the circular hyperbolic roof is no longer negative, and both positive and negative values exist. The roof surface is affected by wind suction, rain pressure, and wind pressure. Under different wind direction angles, the average pressure coefficient at the front end of the surface is larger, and the average pressure coefficient at the middle of the roof surface is about zero.

(4) It can be seen from Figure 9:

At a wind direction angle of $0^{\circ}$, the front end of the roof has a gradient distribution, and the average pressure coefficient decreases. Most of the distribution in the middle has no obvious rules. The end of the roof has a gradient distribution and changes greatly, and the average pressure coefficient increases. The average pressure coefficient of the roof surface is mainly positive, and the maximum average pressure coefficient of the roof surface appears at the end of the roof. At $30^{\circ}$, the average pressure coefficient of the roof surface first decreases and then increases. The average pressure coefficient at the front end of the roof surface is large, ladder-shaped, and the gradient changes rapidly, and the end of the roof changes slowly. At $45^{\circ}$ and $60^{\circ}$, the roof surface is distributed like inverted cone and regular cone, and the average pressure coefficient at the front end of the roof is larger. At $90^{\circ}$, there is no obvious regular distribution on the roof surface.

The elliptical hyperbolic roofs are subject to wind suction, rain pressure, and wind pressure. The average pressure coefficient of the surface of the elliptical hyperbolic roof does not increase with increasing angle, but the average pressure coefficient at the front end of the roof surface is larger.

\subsection{The Influence of Wind Speed on the Pressure Distribution} of Hyperbolic Roofs. In this section, the calculation models M1, M2, M3, and M4 are selected. The calculation conditions are shown in Table 4. The numerical simulation of wind-driven rain on the surfaces of four hyperbolic roofs is performed under different wind speeds, and the average pressure coefficient distribution diagrams are shown in Figures 10-13.

It can be seen from Figures 10-13:
TABLE 4: Simulation conditions.

\begin{tabular}{lccc}
\hline Condition & Wind speed & Wind direction angle & Rainfall intensity \\
\hline $\mathrm{a}$ & $10 \mathrm{~m} / \mathrm{s}$ & & \\
$\mathrm{b}$ & $15 \mathrm{~m} / \mathrm{s}$ & $0^{\circ}$ & $22 \mathrm{~mm} / \mathrm{h}$ \\
$\mathrm{c}$ & $20 \mathrm{~m} / \mathrm{s}$ & & \\
\hline
\end{tabular}

(1) Under different wind speeds, the change law and trend of the average pressure coefficient curve on the surface of square and rectangular hyperbolic roofs are similar. Direction 1: the average pressure coefficient of the roof surface increases with the increase of wind speed, but the change range is small; the average pressure coefficient at the front edge of the roof surface is the largest and gradually decreases along the longitudinal direction of the roof. Direction 2: the curve is a parabola with an upward opening, and the average pressure coefficient of the roof surface of the windward surface increases with the increase of wind speed; the maximum average pressure coefficient appears in the middle of the roof, and the average pressure coefficient increases first and then decreases. It is the parabola of the airflow along the center line and the opening upwards. The airflow is separated at a low height, and the attachment is strong. When the wind speed is $20 \mathrm{~m} / \mathrm{s}$, the average pressure coefficient is much larger than the average pressure coefficient at other speeds.

(2) Under different wind speeds, the change law and trend of the surface average pressure coefficient curve of the circular and elliptical hyperbolic roofs in direction 1 are similar. The average pressure coefficient decreases rapidly first, then stabilizes, and finally increases. The maximum value is at the end of the roof. The average pressure coefficient of the curve has not only negative values, but also more positive values, which means that the roof surface is also affected by pressure in addition to suction. It is also subject to pressure; the greater the wind speed, the larger the average pressure curve. The main reason is that the wind speed is greater, the kinetic energy of the raindrops is greater, and the more the raindrops on the roof, the greater the pressure. In direction 2 , the average pressure distribution of the circular hyperbolic roof has no obvious rules, indicating that the effect of wind-driven rain is more complicated. The maximum average pressure coefficient is also at the roof end.

(3) Under different wind speeds, the average pressure coefficient of the hyperbolic roof with the same projection shape has the same change trend, and its tendency is almost not affected by the wind speed. The greater the wind speed, the greater the average pressure coefficient, the greater the force applied to the roof surface, and the higher the risk of damage. 


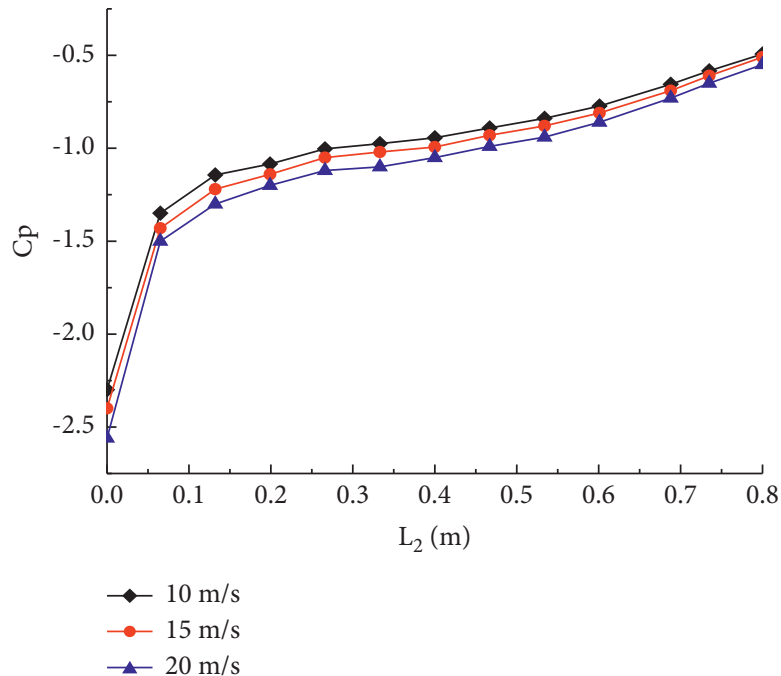

(a)

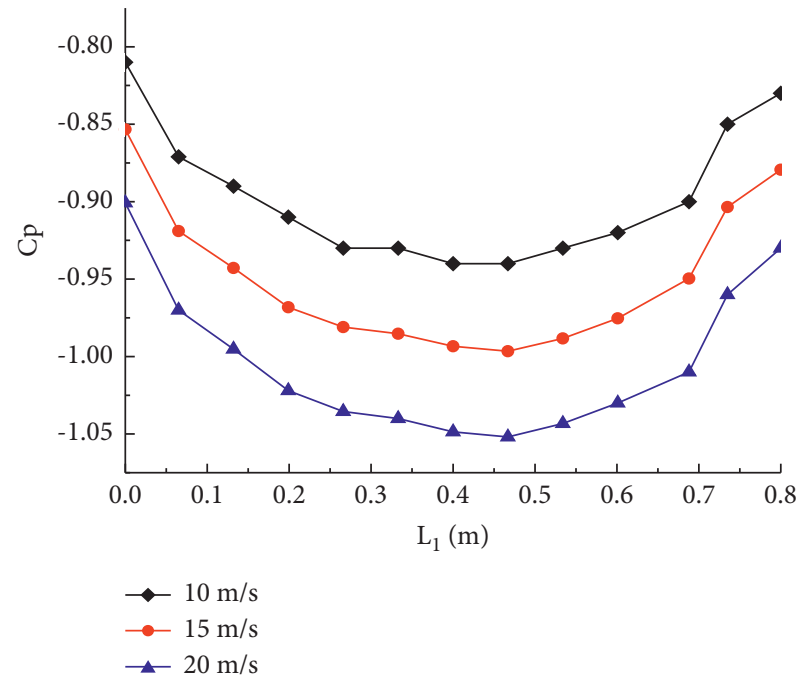

(b)

Figure 10: Contrast curve of $C_{p}$ on the surface of the square hyperbolic roof. (a) Direction 1. (b) Direction 2.

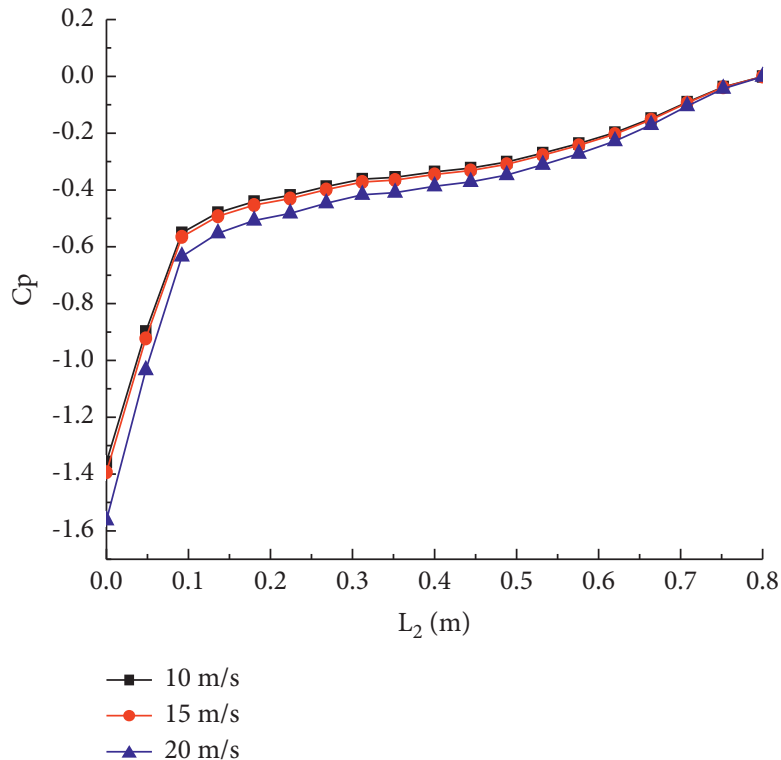

(a)

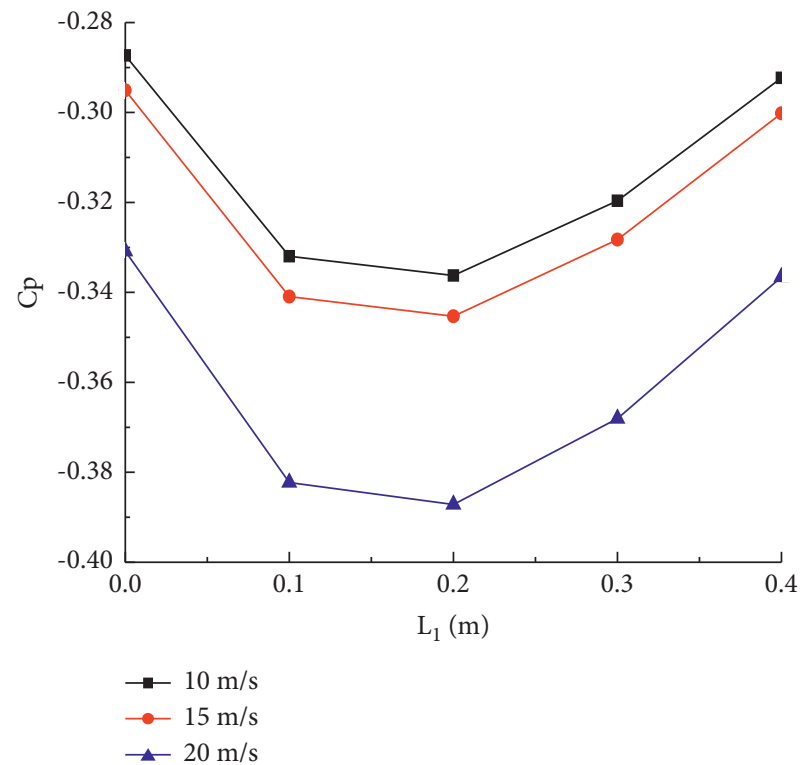

(b)

Figure 11: Contrast curve of $C_{p}$ on the surface of the rectangular hyperbolic roof. (a) Direction 1. (b) Direction 2.

3.4. The Influence of Rainfall Intensity on the Pressure Distribution of Hyperbolic Roofs. In this section, the calculation models M1, M2, M3, and M4 are selected. The calculation conditions are shown in Table 5. The numerical simulation of wind-driven rain on the surfaces of four hyperbolic roofs is performed under different rainfall intensity, and the average pressure coefficient distribution diagrams are shown in Figures 14-17.

It can be seen from Figures 14-17:

(1) Direction 1: The average pressure coefficient curves of the roof surface under different rainfall intensities tend to be approximately the same, and the curve decreases first, then stabilizes, then increases finally. The greater the rainfall intensity, the greater the average pressure coefficient curve. This is because the greater the rainfall intensity, the larger the number of raindrops, the greater the kinetic energy of the raindrops, and the greater the force of raindrops hitting the roof surface. The average pressure coefficient is the largest at the surface end of the roof. The main reason is that the airflow has a strong separation effect at the roof end. The average pressure coefficient changes from negative value to positive 


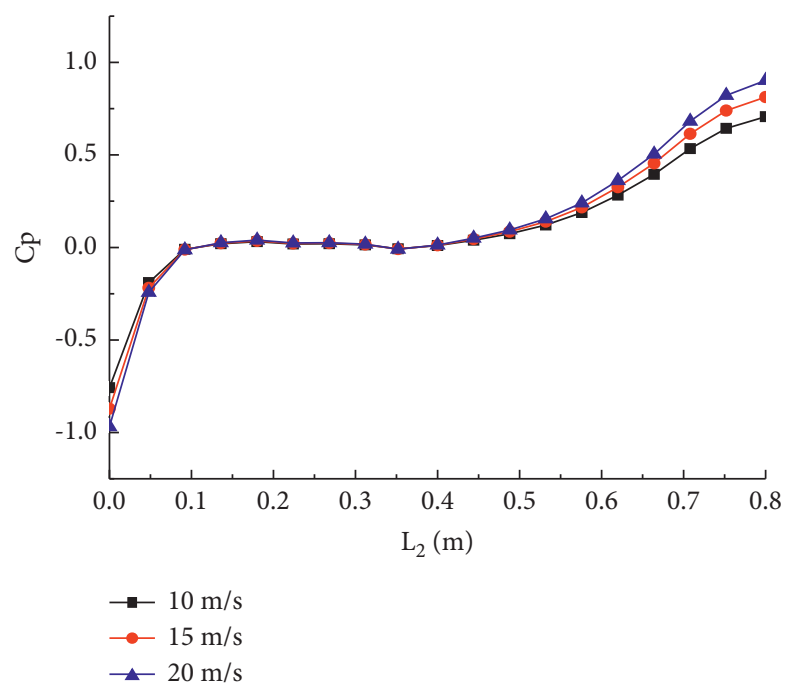

(a)

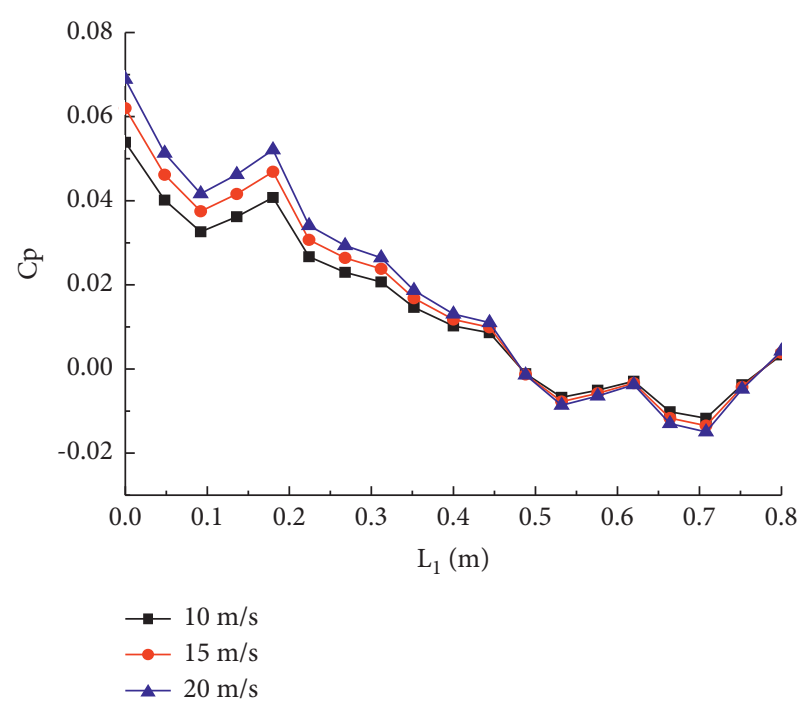

(b)

Figure 12: Contrast curve of $C_{p}$ on the surface of the circular hyperbolic roof. (a) Direction 1. (b) Direction 2.

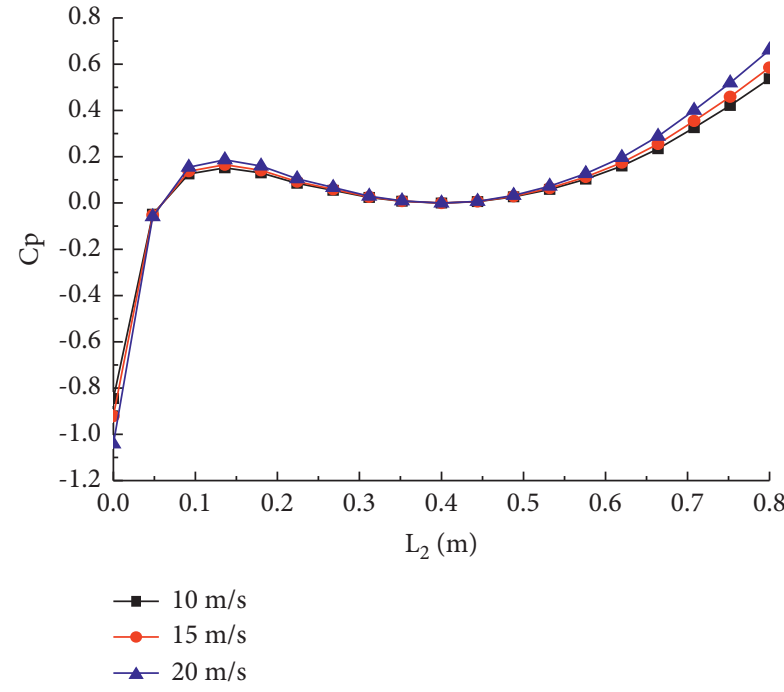

(a)

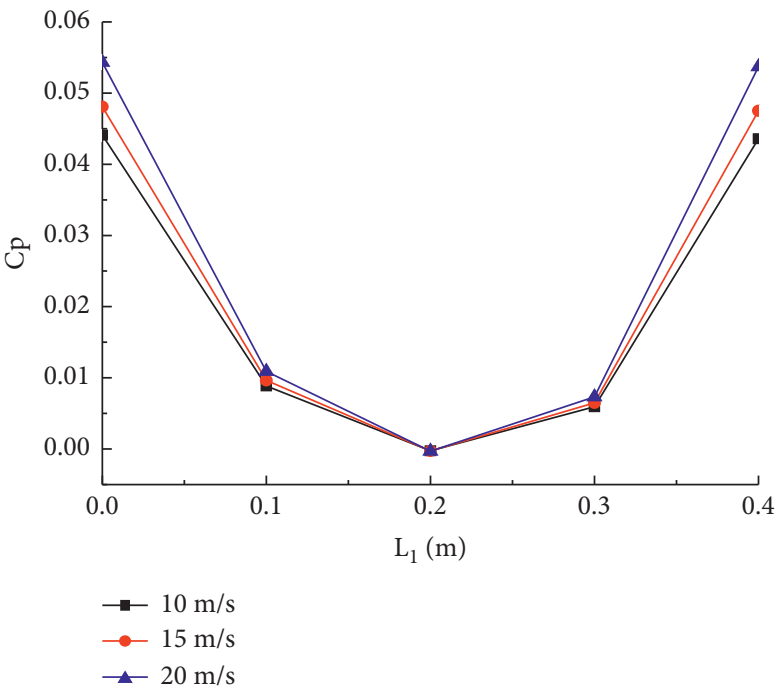

(b)

Figure 13: Contrast curve of $C_{p}$ on the surface of the elliptical hyperbolic roof. (a) Direction 1. (b) Direction 2.

TABLE 5: Simulation conditions.

\begin{tabular}{lccc}
\hline Condition & Rainfall intensity & Wind direction angle & Wind speed \\
\hline a & $32 \mathrm{~mm} / \mathrm{h}$ & & \\
$\mathrm{b}$ & $64 \mathrm{~mm} / \mathrm{h}$ & $0^{\circ}$ & $10 \mathrm{~m} / \mathrm{s}$ \\
$\mathrm{c}$ & $100 \mathrm{~mm} / \mathrm{h}$ & & \\
\hline
\end{tabular}

value, because the roof surface is affected by wind suction, rain pressure, and possibly wind pressure.

(2) Direction 2: The average pressure coefficient curve trend is roughly the same under different rainfall intensity. The average pressure coefficient of the square and rectangular roof surface decreases as the rainfall intensity decreases. The parabolic curve first increases to the maximum value and then gradually decreases. The reason is that the airflow has a strong separation effect in the middle, and the average pressure coefficient reaches the maximum value. The average pressure coefficient curve of the circular roof under different rainfall intensities increases and decreases, and the average pressure coefficient at the surface end of the elliptical roof is the largest, which is positive, indicating that there is more pressure. 


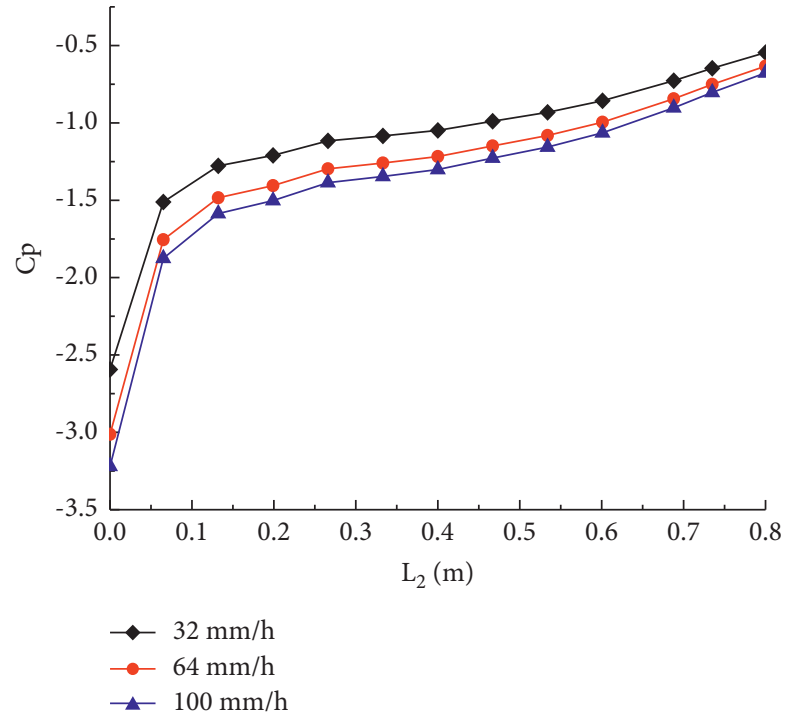

(a)

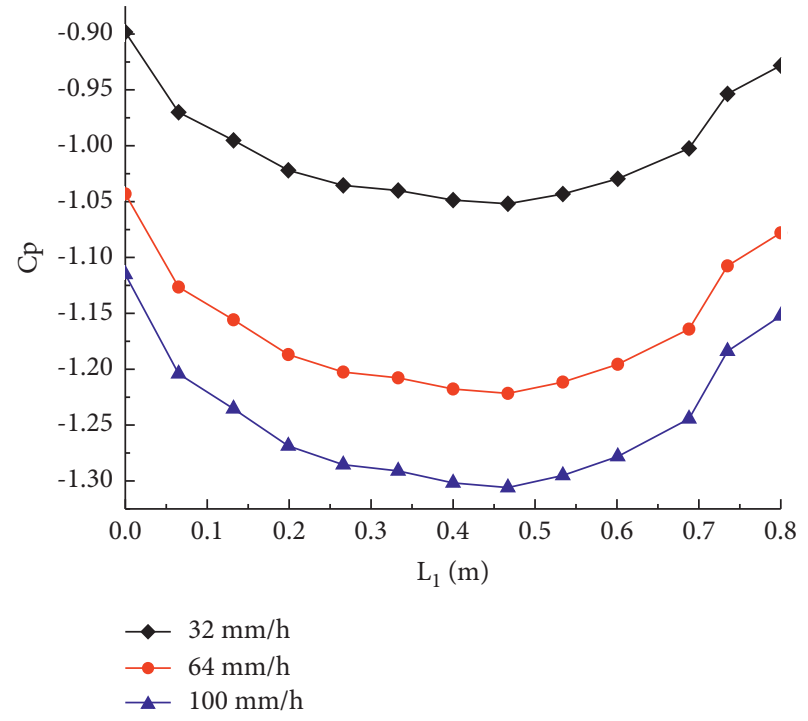

(b)

Figure 14: Contrast curve of $C_{p}$ on the surface of the square hyperbolic roof. (a) Direction 1. (b) Direction 2.

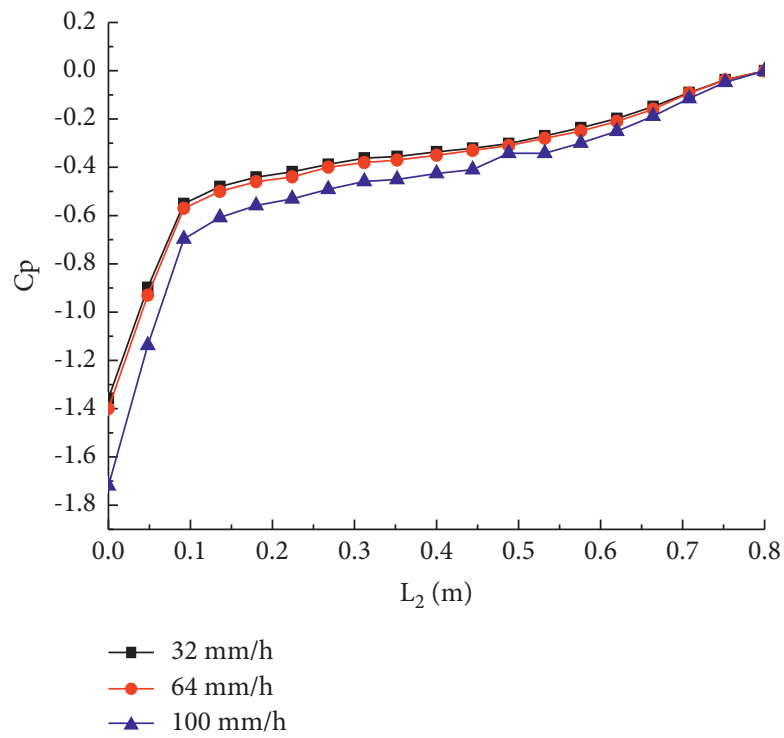

(a)

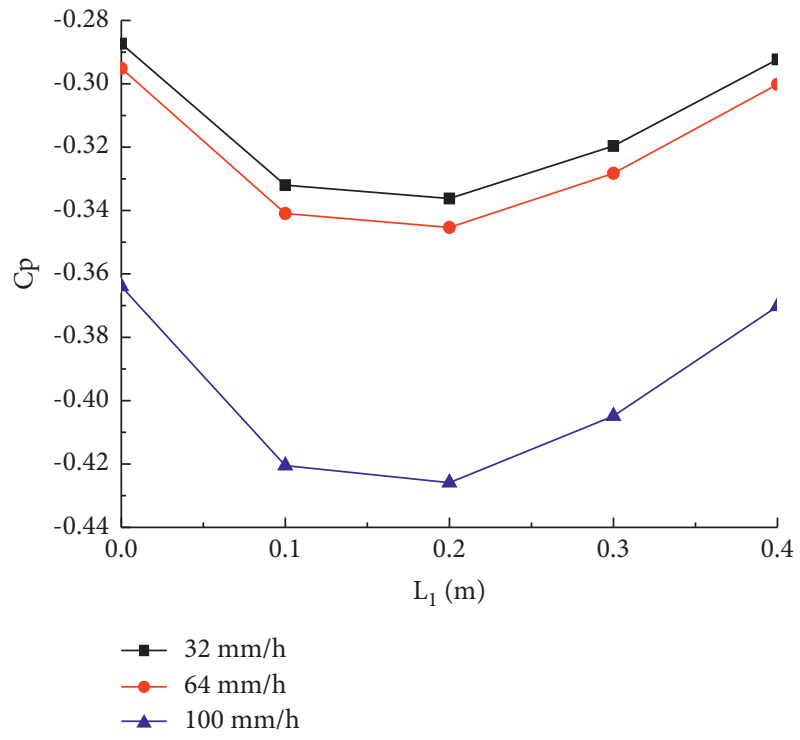

(b)

Figure 15: Contrast curve of $C_{p}$ on the surface of the rectangular hyperbolic roof. (a) Direction 1. (b) Direction 2.

\section{The Recommended Values of the Average Pressure Coefficient of the Large-Span Hyperbolic Roof}

In this section, the calculation models M1, M2, M3, and M4 are selected. The calculation conditions are shown in Table 6. The roof is evenly divided into five columns along the $l$ direction as $a, b, c, d$, and $e$. The detailed layout of the measuring points is shown in Figure 18 below. Since the airflow direction is the central axis of the roof, and the roof surface is symmetrical along the center line, the average pressure coefficient curves of columns a and $e$ are the same, and the average pressure coefficient curves of columns $b$ and $d$ are the same, as shown in Figure 19.

It can be seen from Figure 19:

(1) Square and rectangular hyperbolic roofs: The average pressure coefficients of columns $a / e, b / d$, and $c$ are all negative, indicating that they are subjected to wind suction. The average pressure coefficient at the front end of the $a / e, b / d$, and $c$ rows of the windward surface is the largest, and then the average pressure coefficient of the $a / e, b / d$, and $c$ rows gradually decreases with the direction of the airflow, and the separation and reattachment of the airflow at the end 


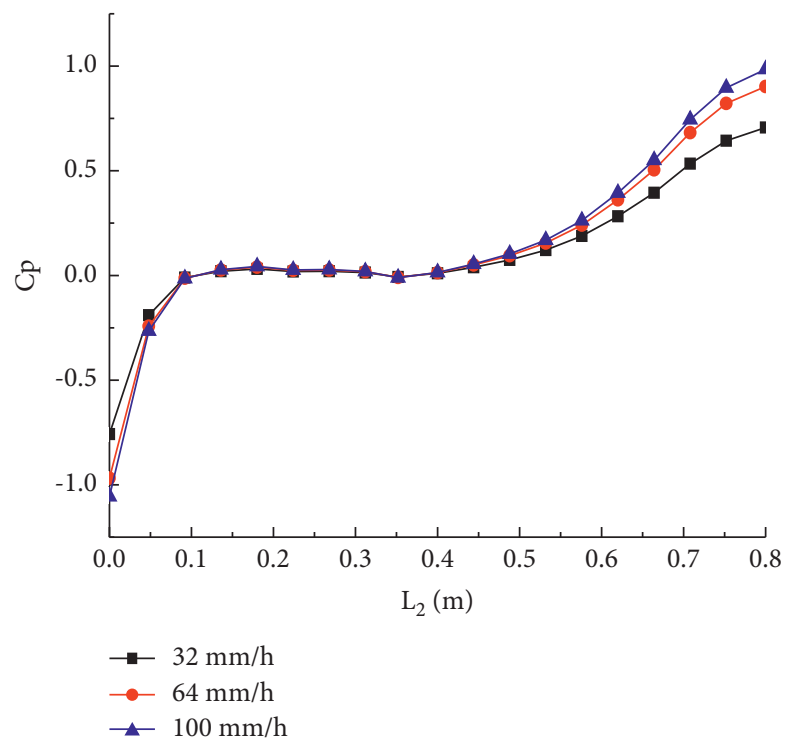

(a)

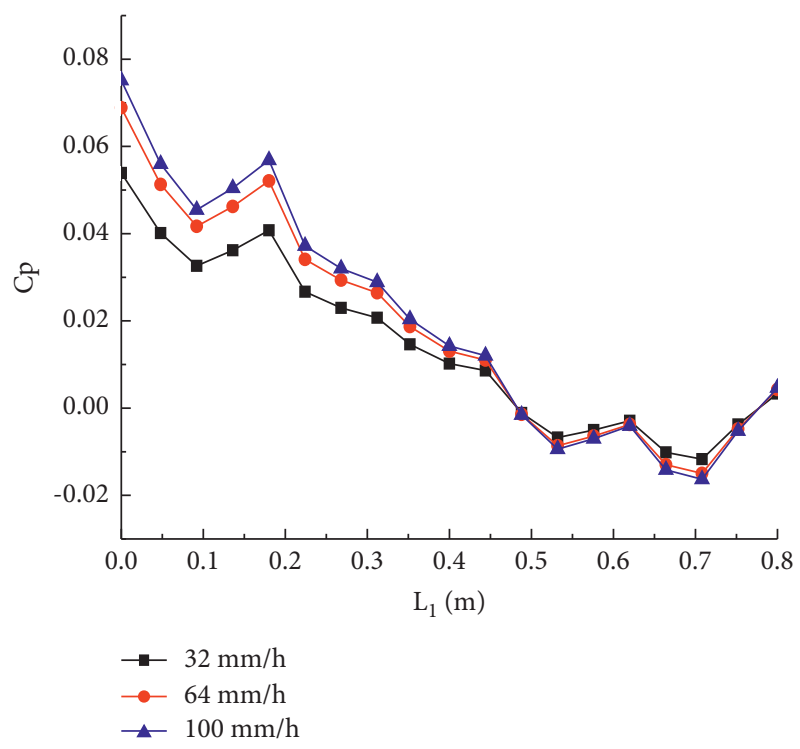

(b)

Figure 16: Contrast curve of $C_{p}$ on the surface of the circular hyperbolic roof. (a) Direction 1. (b) Direction 2.

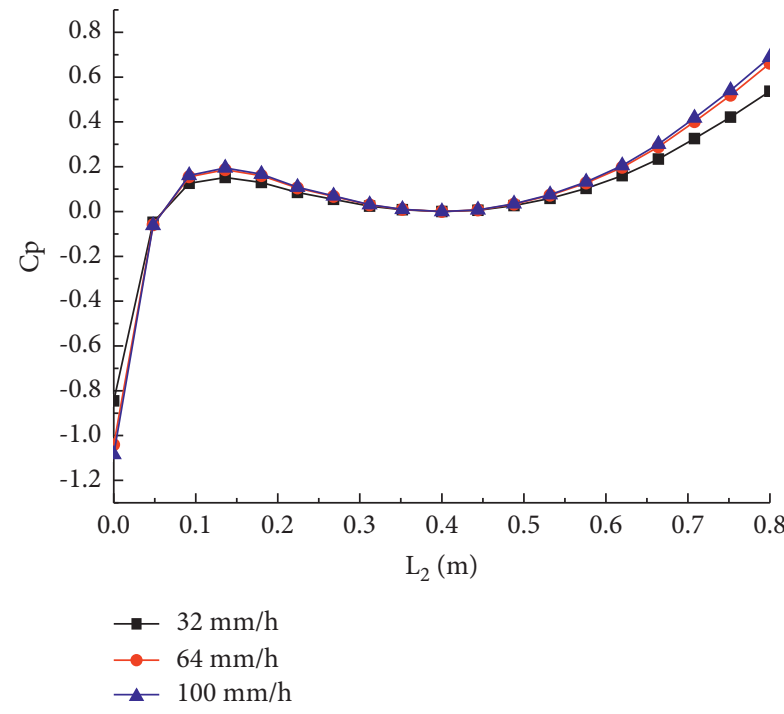

(a)

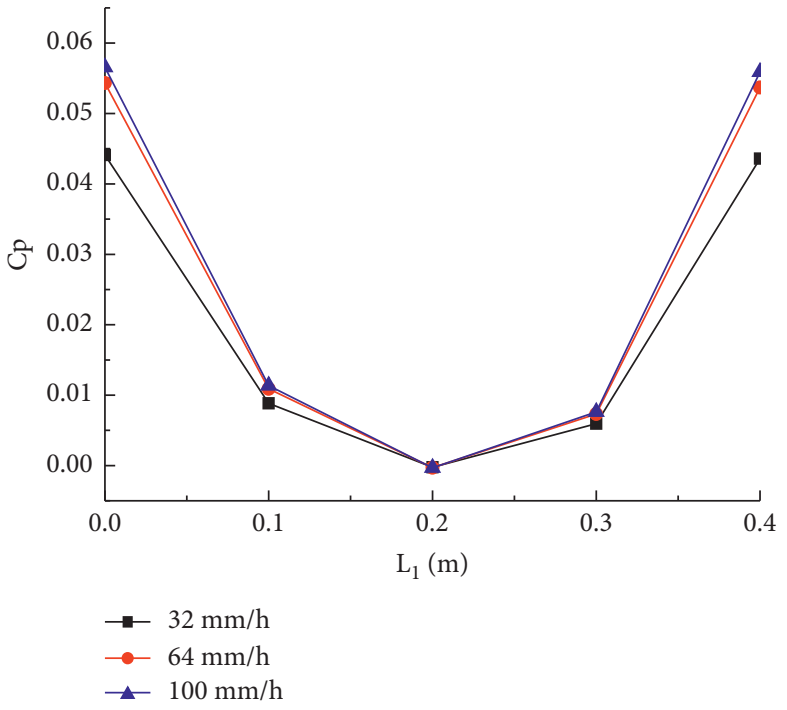

(b)

Figure 17: Contrast curve of $C_{p}$ on the surface of the elliptical hyperbolic roof. (a) Direction 1. (b) Direction 2.

TABLE 6: Simulation conditions.

\begin{tabular}{lcccc}
\hline Condition & Model & $\begin{array}{c}\text { Wind direction } \\
\text { angle }\end{array}$ & $\begin{array}{c}\text { Wind } \\
\text { speed }\end{array}$ & Rainfall intensity \\
\hline$a$ & M1 & & & \\
$b$ & M2 & $0^{\circ}$ & $20 \mathrm{~m} / \mathrm{s}$ & $100 \mathrm{~mm} / \mathrm{h}$ \\
$c$ & M3 & & & \\
$d$ & M4 & & & \\
\hline
\end{tabular}

of the roof have a great effect. The average pressure coefficient at the end a/e of the roof is larger than that of the other columns, because the airflow flows down the parabola of the opening, the height of the roof at the end of the roof is low, and the separation effect of the airflow is strong.

(2) Circular and elliptical roofs: V/e maintains a generally stable trend: the trend of the curves in columns $b / d$ and $c$ is approximately the same. The curves decrease first to 0 , then tend to a stable state, and finally increase. The maximum average pressure coefficient is at the end of the curve, and the airflow plays a greater role at the end. The curve in column $c$ is larger than the average pressure coefficient curve in columns a/e and $b / d$. The main reason is that the 


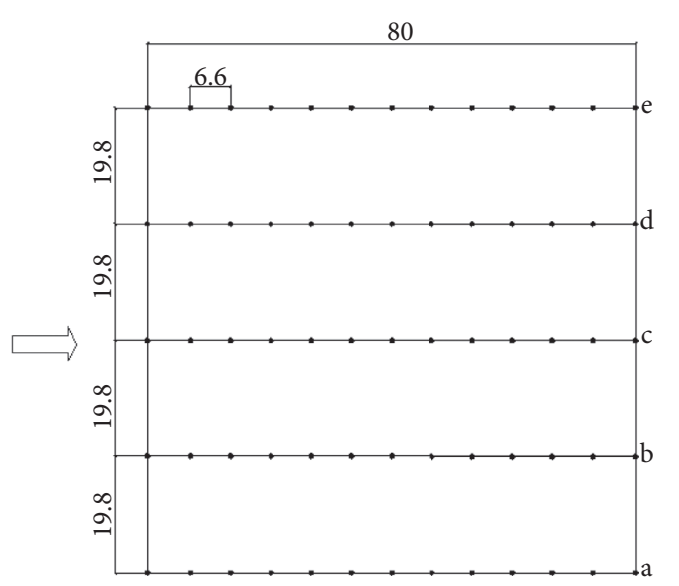

(a)

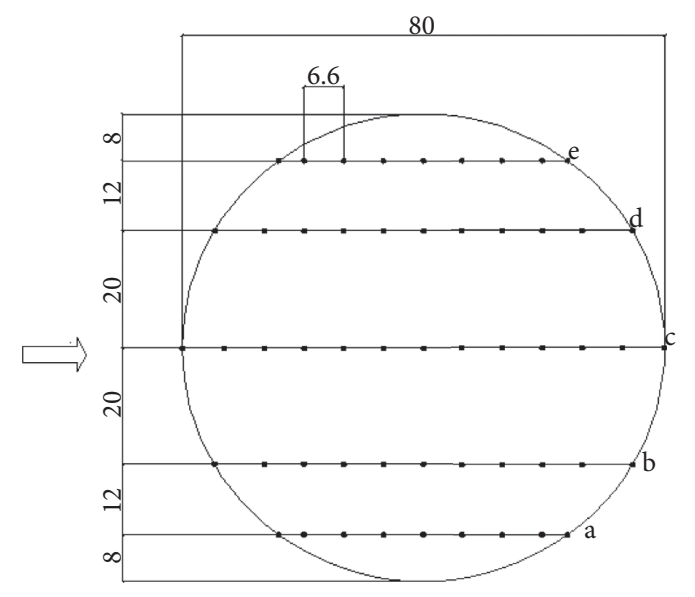

(c)

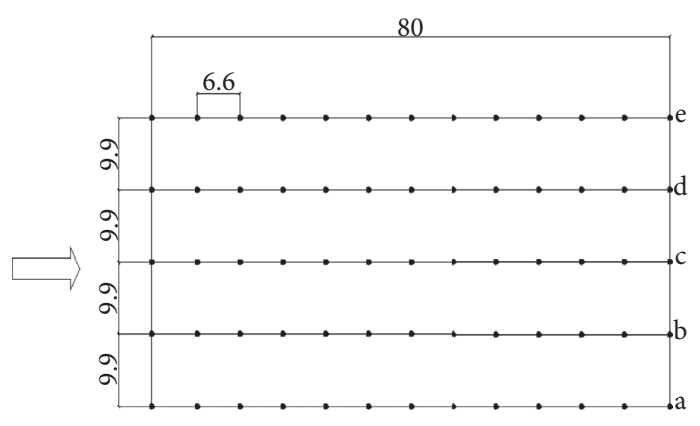

(b)

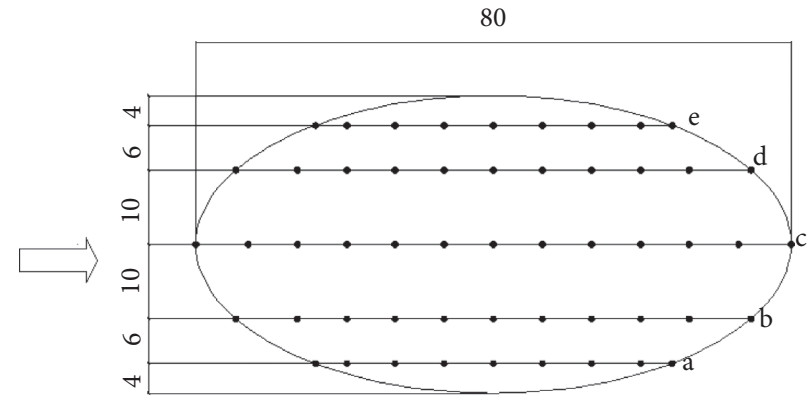

(d)

FIGURE 18: The distribution of measuring points on hyperbolic roofs. (a) Square hyperbolic roof (M1). (b) Rectangular hyperbolic roof (M2). (c) Circular hyperbolic roof (M3). (d) Elliptical hyperbolic roof (M4).

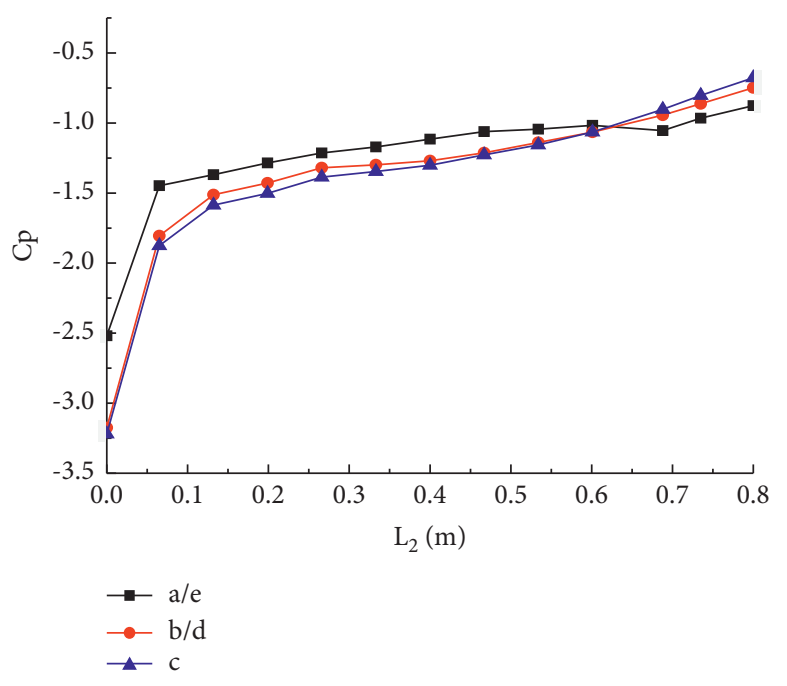

(a)

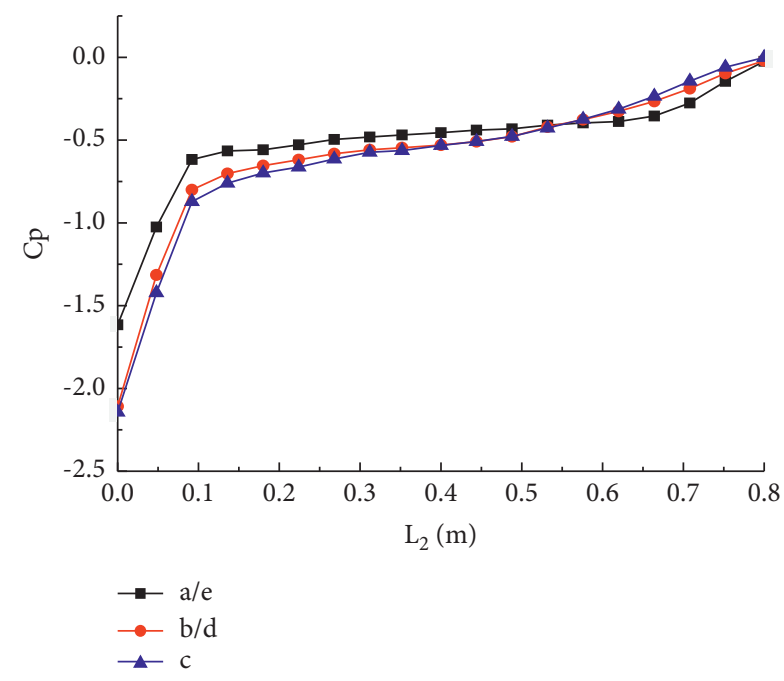

(b)

Figure 19: Continued. 


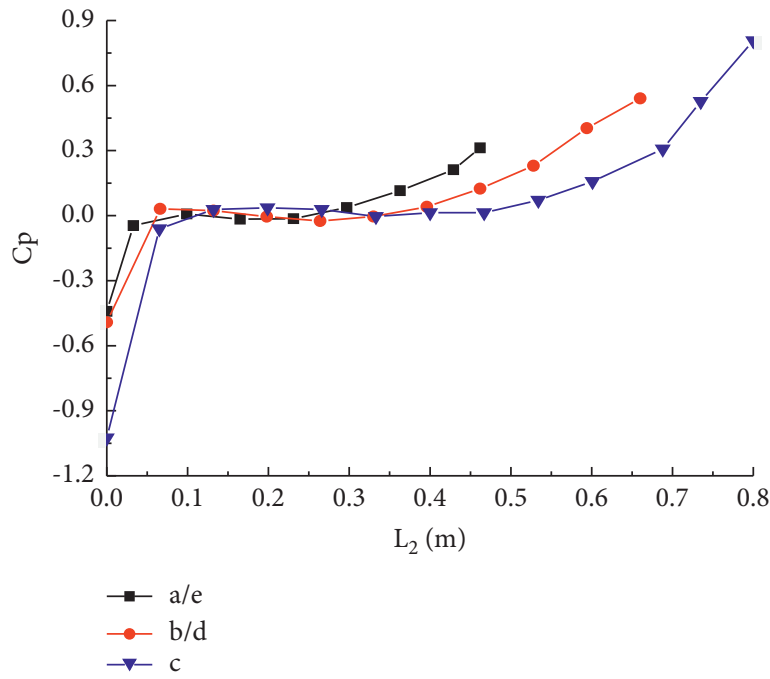

(c)

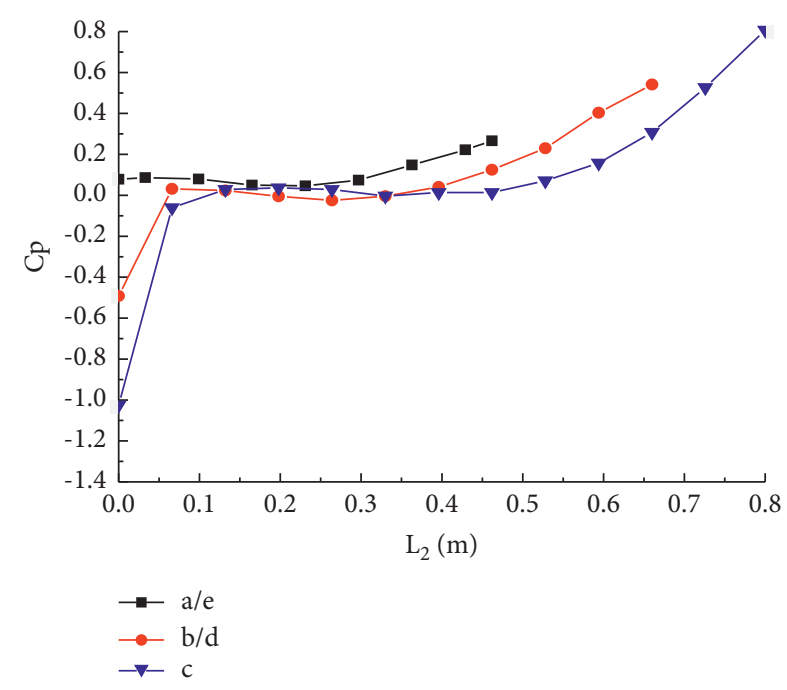

(d)

FiguRE 19: The graph of average pressure coefficient on hyperbolic roofs. (a) Square hyperbolic roof (M1). (b) Rectangular hyperbolic roof (M2). (c) Circular hyperbolic roof (M3). (d) Elliptical hyperbolic roof (M4).

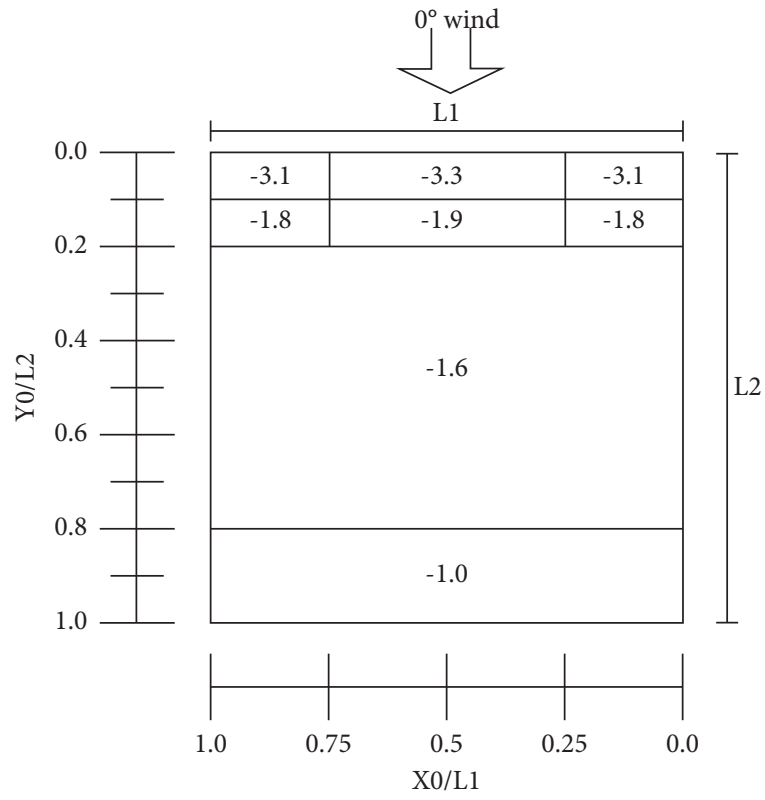

(a)

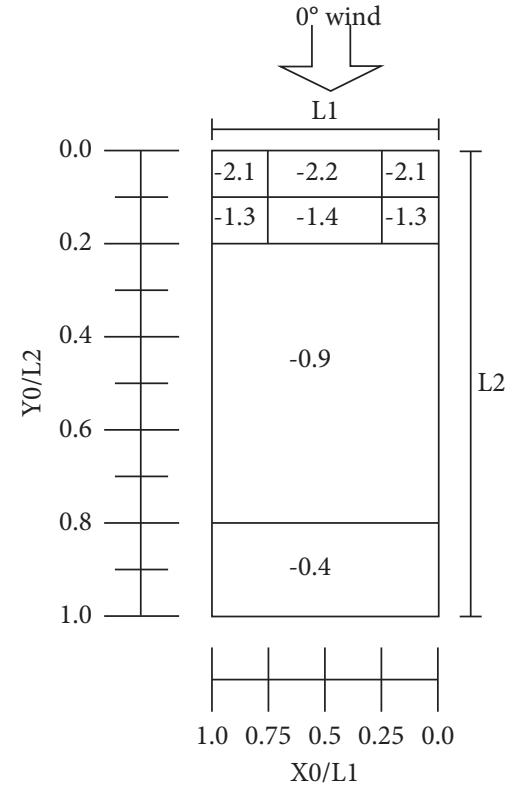

(b)

Figure 20: Continued. 


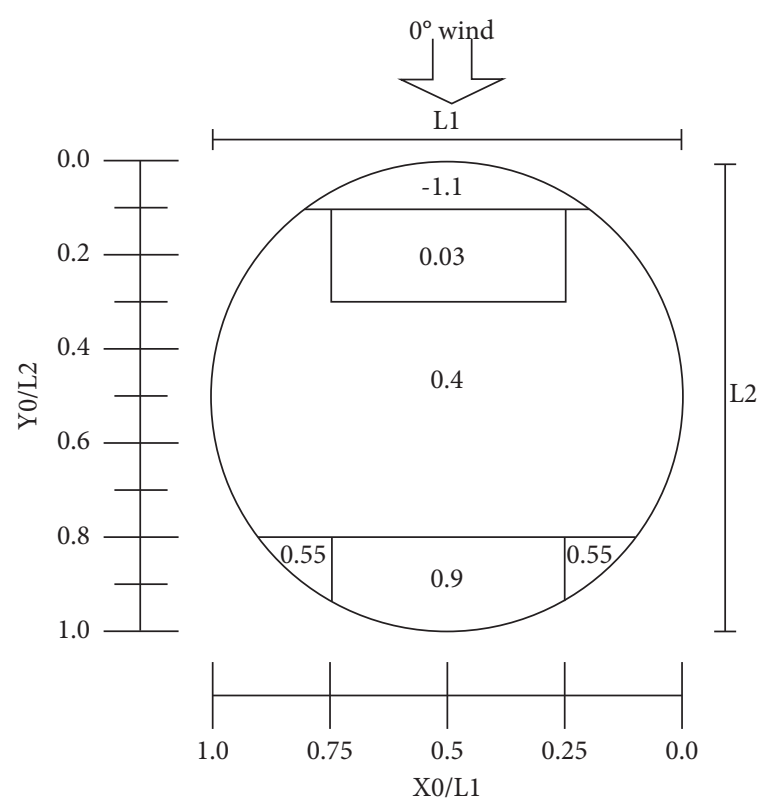

(c)

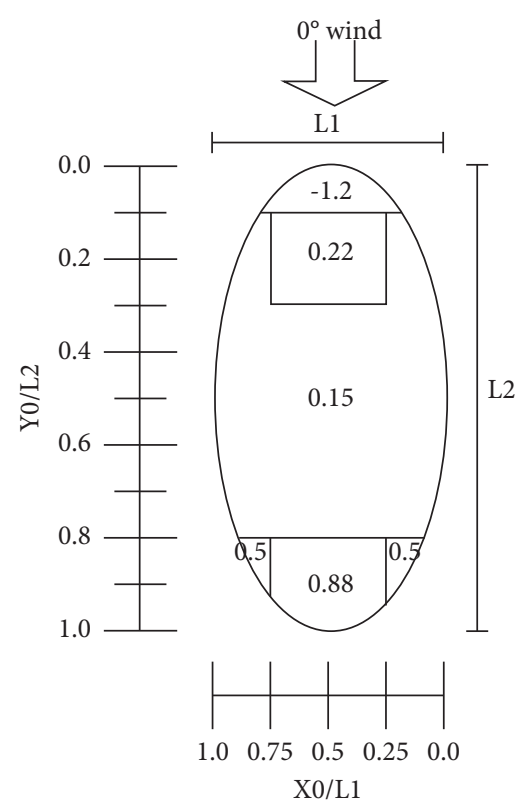

(d)

FIgURE 20: The recommended value of the average pressure coefficient on hyperbolic roofs. (a) Square hyperbolic roof. (b) Rectangular hyperbolic roof. (c) Circular hyperbolic roof. (d) Elliptical hyperbolic roof.

airflow flows along the centerline of the roof, and $c$ is listed on the centerline, and the airflow has a strong airflow separation effect at a low height.

Through Figures 18 and 19, the hyperbolic roof is partitioned according to the specifications, and the average pressure coefficient is drawn into a graph to provide a reference for the design of weather resistance. The basis for the selection of numerical values: the two adjacent columns of data take large values, and their safety has been guaranteed. The recommended partition value of the average pressure coefficient of the surface of the hyperbolic roof given in Figure 20 is not constrained by the size. The height of the large-span hyperbolic roof is suitable for the design of 20-40 m weather resistance.

\section{Discussion}

In this section, some limitations of this study and suggestions for further research will be presented. The proposed partition value of the average pressure coefficient of the roof surface proposed in this paper is suitable for large-span hyperbolic roofs of about $20 \sim 40 \mathrm{~m}$, but it does not represent all large-span hyperbolic roof structures. So, in the future, we can study the hyperbolic roof structure of other heights to improve the data of this kind of roof structure. In addition, the wind speed of the long-span hyperbolic roof structure adopted in this paper is constant, not pulsating wind, and it is derived from the average pressure distribution. In reality, the wind speed changes with time, so it is very meaningful to study the pressure distribution of the large-span hyperbolic roof structure under the action of pulsating wind. Finally, limited by the conditions, this article uses numerical simulation to study the long-span hyperbolic roof structure under the action of wind-driven rain, without actual measurement and wind tunnel test. Therefore, in the future, we can actively carry out field survey work and wind tunnel test of large-span hyperbolic roof structures under the action of wind-driven rain, combine numerical simulation methods to make comparative analysis, propose more accurate recommendations, and provide a more accurate reference for the design of large-span hyperbolic roof structures against wind and rain.

\section{Conclusions}

This paper adopts the common square, rectangular, circular, and elliptical large-span hyperbolic roofs in engineering to study the average pressure distribution. The influence of different parameters on the average pressure distribution of large-span hyperbolic roofs is studied, and some laws and conclusions are analyzed and summarized. The reasonable zoning recommended values of the roofs are proposed to provide a reference for future actual projects. The specific conclusions are as follows:

(1) Under different wind direction angles, the average pressure coefficients of the surfaces of square and rectangular hyperbolic roofs are all negative, and their surfaces are subjected to suction. The most unfavorable wind direction angle for the square hyperbolic roof structure is $0^{\circ}$, while the average pressure coefficient of the rectangular hyperbolic roof varies with wind direction angle without obvious rules. The average pressure coefficient of circular and elliptical hyperbolic roofs has both 
negative and positive values. The roof is affected by wind suction, rain pressure, and wind pressure.

(2) Under different wind speeds and rainfall intensities, the average pressure coefficient of the hyperbolic roof with the same shape has the same change trend, and the wind speed and rainfall intensity have little effect on the change trend. The greater the wind speed or rainfall intensity, the greater the average pressure coefficient of the hyperbolic roof, and the greater the force on the roof surface, the higher the risk of damage.

(3) The recommended values for the partition of the average pressure coefficient of wind-driven rain of a large-span hyperbolic roof are given, which provide a reference basis for the design of the reference for the design of wind-driven rain on similar hyperbolic roofs.

\section{Data Availability}

The data used to support the findings of this study are included within the article.

\section{Conflicts of Interest}

The authors declare that they have no conflicts of interest.

\section{Acknowledgments}

This study is supported by the National Natural Science Foundations of China (No. 51108345), Guangxi Key Laboratory of Geomechanics and Geotechnical Engineering (GUIKENENG19-Y-21-2), Guangxi Key Laboratory of New Energy and Building Energy Saving Foundation (Gui Keneng 19-J-21-14), GuangXi key Laboratory Fund of Embedded Technology and Intelligent System, Joint Cultivation Program of National Natural Science Foundations of Guangxi (2019GXNSFAA245037), Guangxi Youth Innovative Talents research project (Guike AD19245012), Scientific and Technology Startup Foundation of Guilin University of Technology (GUTQGJJ2019042, GUTQDJJ2019041).

\section{References}

[1] C. Grinderslev, M. Lubek, and Z. Zhang, "Nonlinear fluidstructure interaction of bridge deck: CFD analysis and semianalytical modelling," Wind and Structures, vol. 27, no. 6, pp. 381-397, 2018.

[2] M. Liu, Q. S. Li, and S. H. Huang, "Large eddy simulation of wind-driven rain effects on a large span retractable roof stadium," Journal of Wind Engineering and Industrial Aerodynamics, vol. 195, Article ID 104009, 2019.

[3] Y. Yao, H. Wu, X. Li, B. Zhao, B. Chen, and T. Yi, "A review of the transmission tower-line system performance under typhoon in wind tunnel test," Wind and Structures, vol. 29, no. 2, pp. 87-98, 2019.

[4] R. Cacciotti, S. Pospíšil, S. Kuznetsov, and A. Trush, "A proposed calibration procedure for the simulation of winddriven rain in small-scale wind tunnel," Experimental Techniques, vol. 43, no. 4, pp. 369-384, 2019.
[5] L. Li, A. Kareem, Y. Xiao, L. Song, and C. Zhou, "A comparative study of field measurements of the turbulence characteristics of typhoon and hurricane winds," Journal of Wind Engineering and Industrial Aerodynamics, vol. 140, pp. 49-66, 2015.

[6] S. Charisi, T. K. Thiis, and T. Aurlien, "Full-scale measurements of wind-pressure coefficients in twin medium-rise buildings," Buildings, vol. 9, no. 3, Article ID 116798983, 2019.

[7] E. C. C. Choi, "Simulation of wind-driven-rain around a building," Journal of Wind Engineering and Industrial Aerodynamics, vol. 46-47, pp. 721-729, 1993.

[8] E. C. C. Choi, "Determination of wind-driven-rain intensity on building faces," Journal of Wind Engineering and Industrial Aerodynamics, vol. 51, no. 1, pp. 55-69, 1994.

[9] E. C. C. Choi, "Parameters affecting the intensity of winddriven rain on the front face of a building," Journal of Wind Engineering and Industrial Aerodynamics, vol. 53, no. 1-1, pp. 1-17, 1994.

[10] E. C. C. Choi, "Numerical modelling of gust effect on winddriven rain," Journal of Wind Engineering and Industrial Aerodynamics, vol. 72, pp. 107-116, 1997.

[11] E. C. C. Choi, "Wind-driven rain on building faces and the driving-rain index," Journal of Wind Engineering and Industrial Aerodynamics, vol. 79, no. 1-2, pp. 105-122, 1999.

[12] E. C. C. Choi, "Modelling of wind-driven rain and its soil detachment effect on hill slopes," Journal of Wind Engineering and Industrial Aerodynamics, vol. 90, no. 9, pp. 1081-1097, 2002.

[13] R. Sankarana and D. A. Paterson, "Computation of rain falling on a tall rectangular building," Journal of Wind Engineering and Industrial Aerodynamics, vol. 72, pp. 127-136, 1997.

[14] X. P. Wu, Numerical simulation study on the effect of wind and rain on low-rise buildings, Ph.D. Dissertation, Zhejiang University, Hangzhou, China, 2012.

[15] A. Kubilay, D. Derome, B. Blocken, and J. Carmeliet, "CFD simulation and validation of wind-driven rain on a building facade with an Eulerian multiphase model," Building and Environment, vol. 61, pp. 69-81, 2013.

[16] A. Kubilay, D. Derome, B. Blocken, and J. Carmeliet, "Highresolution field measurements of wind-driven rain on an array of low-rise cubic buildings," Building and Environment, vol. 78, pp. 1-13, 2014.

[17] K. Pettersson, S. Krajnovic, A. S. Kalagasidis, and P. Johansson, "Simulating wind-driven rain on building facades using Eulerian multiphase with rain phase turbulence model," Building and Environment, vol. 106, pp. 1-9, 2016.

[18] H. Wang, X. Hou, and Y. Deng, "Numerical simulations of wind-driven rain on building facades under various oblique winds based on Eulerian multiphase model," Journal of Wind Engineering and Industrial Aerodynamics, vol. 142, pp. 82-92, 2015.

[19] H. Wang, W. Song, and Y. Chen, "Numerical simulation of wind-driven rain distribution on building facades under combination layout," Journal of Wind Engineering and Industrial Aerodynamics, vol. 188, pp. 375-383, 2019.

[20] Wind Resistant Design, AIJ Recommendations for Loads on Buildings, Architectural Institute of Japan, Tokyo, Japan, 2004.

[21] D. A. de Wolf, "On the Laws-Parsons distribution of raindrop sizes," Radio Science, vol. 36, no. 4, pp. 639-642, 2001.

[22] C. Matzler, "Drop-size distributions and mie computations for rain,” Research Report No. 2002-16, Institute of Applied Physics, University of Bern, Bern, Switzerland, 2002.

[23] M. Abuku, B. Blocken, K. Nore, J. V. Thue, J. Carmeliet, and S. Roels, "On the validity of numerical wind-driven rain 
simulation on a rectangular low-rise building under various oblique winds," Building and Environment, vol. 44, no. 3, pp. 621-632, 2009.

[24] F. Rizzo, P. D'Asdia, and G. Bartoli, "Characterisation of pressure coefficients on hyperbolic paraboloid roofs," Journal of Wind Engineering and Industrial Aerodynamics, vol. 102, pp. 61-71, 2012.

[25] F. Rizzo, P. D’Asdia, M. Lazzari, and L. Procino, "Wind action evaluation on tension roofs of hyperbolic paraboloid shape," Engineering Structures, vol. 33, no. 2, pp. 445-461, 2011.

[26] F. Rizzo and F. Ricciardelli, "Design pressure coefficients for circular and elliptical plan structures with hyperbolic paraboloid roof," Engineering Structures, vol. 139, pp. 153-169, 2017. 